\title{
DIETA EN SOCIEDADES ALFARERAS DE CHILE CENTRAL: APORTE DE ANÁLISIS DE ISÓTOPOS ESTABLES
}

\author{
DIET IN POTTERY-MAKING SOCIETIES FROM CENTRAL CHILE: \\ THE CONTRIBUTION OF STABLE ISOTOPE ANALYSES
}

\author{
Fernanda Falabella ${ }^{1}$, M. Teresa Planella ${ }^{2}$ Eugenio Aspillaga ${ }^{1}$, Lorena Sanhueza ${ }^{1}$ y Robert H. Tykot ${ }^{3}$
}

\begin{abstract}
Este trabajo pretende contribuir al conocimiento de los sistemas de subsistencia y asentamiento de las poblaciones alfareras prehispanas de Chile central, sobre la base de análisis de isótopos estables de carbono, nitrógeno y oxígeno realizados en hueso y dientes humanos. Dicha técnica no se había aplicado anteriormente en esta región y, a diferencia de la información inferida de restos botánicos, faunísticos y artefactuales de sitios arqueológicos, así como de patologías óseas y dentales, permitió reconocer y dimensionar lo que los individuos estudiados realmente consumieron. Los datos humanos fueron interpretados a la luz de las señales isotópicas de los recursos vegetales y faunísticos de Chile central que fueron analizados con la misma metodología. Los principales aportes son: evidencia concreta de patrones alimentarios diferenciados según grupo cultural; baja dependencia en los recursos marinos de casi todos los habitantes costeros; evidencia indirecta de patrones de movilidad costa-interior que muestran diferencias entre las poblaciones del período Alfarero Temprano y del Intermedio Tardío; aumento del consumo de maíz a lo largo de la secuencia temporal especialmente en la población Aconcagua; diferencias de género en el consumo de maíz entre esta misma población, con mayor consumo entre individuos masculinos. Los resultados confirman algunas hipótesis previamente planteadas, como la diferencia en las dietas de poblaciones contemporáneas Bato y Llolleo del período Alfarero Temprano, cuestionan otras, como la dependencia de los habitantes costeros de los alimentos marinos y abren nuevas preguntas que deberán explorarse en futuras investigaciones.
\end{abstract}

Palabras claves: isótopos estables, arqueología, dieta, Chile central.

This is the first time that stable carbon, nitrogen and oxygen isotope analyses of human bones and teeth have been used to reconstruct subsistence and settlement patterns of prehispanic ceramic societies from Central Chile. Isotope analyses, unlike the evidence from botanical, faunal and artifactual remains from archaeological sites, and from dental and skeletal pathologies, gave information of which resources were really eaten by each individual during the last years of their life. The human data were evaluated against isotopic values of marine and terrestrial resources from central Chile. These results were interpreted taking into consideration different lines of paleodiet evidence. The main contributions are: empirical evidence of dietary differences according to cultural groups; low dependence on marine foods for most people living on the coast; indirect evidence of mobility strategies that show differences between Early and Late Intermediate societies; increased dependence on maize with time, especially among the Aconcagua people; gender differences in maize consumption for the same Aconcagua groups, men showing the greatest levels of maize intake. The results support some hypotheses, such as the difference in dietary patterns between contemporary Bato and Lolleo groups, contradict others, such as the supposed importance of marine diet for coastal inhabitants, and open new research questions for the future.

Key words: Stable isotopes, archaeology, diet, Central Chile.

Los patrones de subsistencia son una característica importante del comportamiento humano que dependen tanto del entorno como de las tecnologías y de las opciones culturales de cada grupo social. En la arqueología de Chile central estos patrones se han caracterizado sobre la base de evidencias botánicas, de arqueofauna, de artefactos encontrados en los sitios arqueológicos, las potencialidades del entorno natural y las patologías óseas y dentales principalmente. Estas evidencias indi- rectas son importantes y útiles, pero también tienen sus limitaciones. Los restos botánicos y faunísticos recuperados en los sitios arqueológicos no reflejan necesariamente los alimentos consumidos ni las proporciones en que éstos se consumieron. Por otra parte, la preservación diferencial de distintos tipos de alimentos hace que algunos estén sobrevalorados y otros subevaluados o totalmente ausentes en el registro, todo lo cual dificulta y sesga la interpretación.

1 Departamento de Antropología, Facultad de Ciencias Sociales, Universidad de Chile, Ignacio Carrera Pinto 1045, Ñuñoa, Santiago.ffala@entelchile.net; loresan@vtr.net; easpilla@uchile.cl

2 Sociedad Chilena de Arqueología, El Amancai 505, Las Condes, Santiago. mtplanella@123mail.cl

3 Department of Anthropology, University of South Florida, 4202 E. Fowler Ave., SOC 107, Tampa, FL 33620, USA. rtykot@chuma1.cas.usf.edu 
Desde los años setenta se han empezado a usar, en arqueología, las proporciones entre isótopos estables de carbono $\left({ }^{12} \mathrm{C} /{ }^{13} \mathrm{C}\right){ }^{1}$ y nitrógeno $\left({ }^{14} \mathrm{~N} /{ }^{15} \mathrm{~N}\right)$ para identificar patrones dietéticos (Vogel y van der Merwe 1977; van der Merwe y Vogel 1978; Schoeninger et al. 1983). El fundamento es que la composición isotópica de los tejidos humanos deriva de la ingesta alimenticia diaria y permanece constante aún después de la muerte. La señal isotópica, a diferencia de los métodos convencionales, refleja lo que cada individuo realmente consumió y ha cobrado cada vez más relevancia porque los fundamentos que sustentan la relación entre el contenido del resto humano analizado y las variables dietéticas inferidas han sido comprobados a través de estudios experimentales (Ambrose y Norr 1993; Katzenberg 1992; van der Merwe 1992; Passey et al. 2005; Tieszen y Fagre 1993). Existen diversos modelos (Ambrose y Norr 1993; Katzenberg 1992; Little y Schoeninger 1995; Newsome et al. 2004; Richards y Hedges 1999; Schwarcz 2000; van der Merwe 1992) y un gran volumen de casos publicados en la literatura arqueológica mundial que han demostrado su eficiencia para estimar el peso relativo que tuvieron distintos tipos de alimentos en la dieta de las poblaciones del pasado, por lo que se trata de un método ampliamente validado (Ambrose 1993; Katzenberg 2000).

\section{Isótopos Estables y Reconstrucción de Dietas en Chile Central}

En este trabajo se analizan cinco grupos prehispanos de Chile central: Comunidades Alfareras Iniciales (300 a.C.-200 d.C.), Bato (200 d.C.-900 d.C.), Llolleo (350 d.C.-1.000 d.C.), Aconcagua (1.000-1.450 d.C.) y de contacto inca (1.450-1.550 d.C.). Estos grupos ocuparon el mismo espacio y los mismos ambientes, tanto en la costa como en el interior, y, si bien algunos de ellos son contemporáneos, todos tienen identidades y sistemas culturales diferentes. Los trabajos arqueológicos realizados a la fecha han proporcionado abundante información con la cual se han generado hipótesis sobre sus sistemas de subsistencia y asentamiento (ver más adelante). Con los análisis de isótopos estables se ha buscado aportar información novedosa, centrada en aquellos aspectos en los que las señales isotópicas tienen mejor resolución.

En primer lugar, nos interesa distinguir los componentes marinos y terrestres de las dietas. El nitrógeno es especialmente sensible a estas diferencias porque los nitratos de base de la cadena alimentaria marina son más positivos que el $\mathrm{N}$ atmosférico utilizado por los organismos terrestres y porque el $\mathrm{N}$ se enriquece en cada nivel de la cadena trófica. Al ser ésta más larga en los organismos marinos, el $\delta^{15} \mathrm{~N}$ de las dietas basadas en productos del mar es notoriamente más positivo (Keegan y DeNiro 1988; Schoeninger et al. 1983; Walker y DeNiro 1986). La pregunta central que pretendemos responder en relación a este punto es si los individuos rescatados de sitios costeros y de sitios del interior reflejan una dieta correspondiente con cada uno de estos ambientes a lo largo de sus vidas, o no. Esta información posibilita evaluar las preferencias alimentarias, la intensidad del consumo marino en distintos ambientes, así como la movilidad espacial y social dentro del territorio (Sealy y van der Merwe 1986). La movilidad costa-interior y los patrones de consumo terrestres o costeros serán también evaluados con la información de isótopos de oxígeno. La razón ${ }^{18} \mathrm{O} /{ }^{16} \mathrm{O}$ mantiene las señales isotópicas del agua consumida por los individuos y ésta varía con la mayor o menor cercanía al mar, además de las temperaturas, la altitud y la latitud ${ }^{2}$ (Fricke et al. 1995).

En segundo lugar, nos interesa reconocer la presencia de maíz (Zea mays) en las dietas y la intensidad de su consumo. El maíz es un cultivo importante en la discusión sobre los inicios y consolidación de la agricultura en Chile central. El análisis isotópico permitirá determinar cómo éste se incorporó a la dieta, diferenciando entre un consumo de pequeñas cantidades y uno de mayor envergadura, como base del sustento. Esto es posible a través de la diferencia de los isótopos de carbono entre las plantas de patrón fotosintético C3 (empobrecidas en $\delta^{13} \mathrm{C}$ ) y $\mathrm{C} 4$ (enriquecidas en $\delta^{13} \mathrm{C}$ ) (Squeo y Ehleringer 2004). El maíz es la única planta de patrón fotosintético $\mathrm{C} 4$ de importancia alimentaria que crece en la zona de estudio y se distingue isotópicamente del resto de las plantas silvestres y cultivadas, las que tienen un patrón fotosintético $\mathrm{C} 3$.

En tercer lugar, esperamos estimar la proporción entre carne y vegetales en la dieta, pregunta relevante para comprender los cambios de hábitos alimentarios entre grupos cazadores, recolectores y hortícolas de Chile central y evaluar la importancia de la fauna como aporte de proteínas en la alimentación. El hueso está compuesto de una matriz 
orgánica o colágeno, producida fundamentalmente por la porción proteica de la dieta y de una mineral o apatita, producto de las proteínas, los carbohidratos y las grasas, es decir de la dieta total (Norr 1995). Una disminución en el espaciamiento entre el valor isotópico del carbono del colágeno (Ccol) y la apatita (Cap) tiene como causal primordial la mayor ingesta de proteínas animales (Bocherens 2000; Harrison y Katzenberg 2003; Schwarcz 2000). Del mismo modo un aumento en el $\mathrm{N}$, en condiciones ambientales similares, indica mayor consumo de carne (Ambrose et al. 2003).

Por último nos interesa explorar si la dieta de la etapa juvenil es similar, o no, a la de la adultez. Con ello, más allá de información directa sobre dieta, podremos responder a la pregunta si los individuos se movían entre la costa y el interior y/o si cambiaron su lugar de residencia entre la etapa juvenil y la adultez. Tanto el colágeno como la apatita de los huesos son repuestos constantemente durante la vida del individuo de tal forma que su composición isotópica refleja el promedio de la dieta de los últimos años de la vida de un individuo (Richards y Hedges 1999). El esmalte de los dientes, en cambio, refleja la dieta durante su período de formación (Wright y Schwarcz 1998). Con la comparación de dientes y huesos de un mismo individuo se puede evaluar, entonces, eventuales cambios de subsistencia entre la edad juvenil, correspondiente a la formación del diente analizado, y la adulta del mismo.

Estamos conscientes que los análisis isotópicos no solucionan todas las interrogantes que surgen en la definición de los patrones dietéticos del pasado. Las señales isotópicas, más que "reconstruir" el patrón de subsistencia, facilitan la identificación de perfiles de consumo de distintos alimentos (Keegan 1989), los que deben evaluarse a la luz de la información que entrega la bioantropología, la arqueobotánica, la zooarqueología y los contextos arqueológicos, en especial los artefactos usados en la obtención, procesamiento y consumo de alimentos. La debida integración de toda esta información es lo que permite comprender las complejidades de las formas de alimentación en el pasado.

\section{Modelos de Subsistencia y Movilidad en las Poblaciones Alfareras de Chile Central}

Las investigaciones que hace años se han estado realizando sobre las poblaciones de los perío- dos Alfarero Temprano (Comunidades Alfareras Iniciales, Bato y Llolleo), Intermedio Tardío (Aconcagua) y Tardío (de contacto inca) en la región central de Chile han acumulado una serie de evidencias arqueológicas que han sido la base para generar hipótesis y modelos sobre sus patrones de subsistencia-asentamiento.

Para el período Alfarero Temprano (PAT) se ha propuesto que las Comunidades Alfareras Iniciales mantendrían los patrones de caza-recolección del período Arcaico basándose principalmente en la información de los contextos líticos que reflejarían un énfasis en la caza, la escasez de cultígenos en los análisis arqueobotánicos y el patrón de desgaste dentario (Belmar y Quiroz 1999a, 2003; Falabella y Stehberg 1989; Sanhueza y Falabella 2003; Stehberg 1976). Los grupos Bato, aun siendo productores y usuarios de alfarería, por sus contextos líticos han sido reconocidos como con mayor tradición de caza que sus contemporáneos Llolleo, con un equipamiento de molienda que denota menor envergadura del vegetal procesado (Vásquez 2000) y, si bien han presentado escasas evidencias de especies domesticadas (Chenopodium quinoa) han sido generalmente caracterizados como con una horticultura incipiente (Falabella y Planella 1988-89; Planella y Falabella 1987; Planella y Tagle 2004), donde la caza y la recolección juegan un papel fundamental (Sanhueza et al. 2003). Los grupos Llolleo también alfareros tempranos, han sido considerados con un patrón dietético generalizado con vegetales silvestres (peumo, cocos de palma chilena, poáceas) y domesticados (como Chenopodium quinoa, Zea mays, Phaesolus sp., Cucurbita sp. y Lagenaria sp.), caza y recolección de animales terrestres y que, en la costa, también agregan recursos marinos y algunos de las lagunas litorales (Falabella y Stehberg 1989; Falabella y Planella 1991; Planella 2005). Los contextos de molienda muestran patrones que han sido interpretados como relacionados a una producción más intensiva de harinas (Vásquez 2000) y los análisis de elementos traza en individuos del sitio El Mercurio han sido interpretados como señal de consumo de maíz (Falabella et al. 1995-1996). Sanhueza et al. (2003) concluyen que se trataría de horticultores con cierto grado de sedentarismo.

Desde el punto de vista del asentamiento, los contextos Bato y Llolleo, que representan grupos con identidades sociales bien diferenciadas, han sido reconocidos tanto en áreas costeras como in- 
teriores. Los grupos Bato mantendrían una alta movilidad territorial, en cambio los Llolleo presentarían un sedentarismo de mayor permanencia. En el caso de estos últimos, tanto la información derivada de un estudio comparativo con elementos traza entre individuos del sitio costero LEP-C y el sitio El Mercurio del valle central como el análisis de las materias primas utilizadas para la producción de los conjuntos alfareros, indican poblaciones que habitaron espacios diferenciados a lo largo de su vida (Falabella 2000a; Falabella et al. 1995-1996; Sanhueza 2004).

Para el período Intermedio Tardío (PIT) existe bastante consenso que la población Aconcagua tendría un sistema dietético basado en la horticultura complementada con caza y recolección vegetal y animal y que ellos acceden a los recursos disponibles en el entorno de sus caseríos (Massone et al. 1998; Hermosilla et al. 2003; Planella y Stehberg 1997). Se han registrado prácticamente las mismas especies de plantas domesticadas como macrorrestos en los sitios que se encontraban anteriormente en el PAT (Belmar y Quiroz 1999b, 2000; Durán y Planella 1989; Durán et al. 1993; Planella 1997; Quiroz 2004), aunque una diferencia importante radica en que algunas muestran un aumento de tamaño respecto a especímenes obtenidos de los contextos del PAT (Planella 2005). Por otra parte, en la producción cerámica se aprecia la existencia de grandes continentes probablemente utilizados para almacenar las cosechas y mayor conductividad en las paredes de las ollas para cocinar (Falabella 2000b). Aumentaría también el consumo de guanacos y cambiaría el manejo del animal, aguachándolos próximos a las viviendas (Becker 1993). Estos grupos habitarían preferentemente los valles interiores. Se ha sugerido que, junto con la posible existencia de grupos asentados en forma permanente en el litoral, habría campamentos estacionales a los que llegan grupos del interior, específicamente de los valles de la cordillera de la costa (Falabella et al. 2003).

Para el período Tardío o etapa de aculturación Inca los datos arqueológicos son escasos y las hipótesis derivan fundamentalmente de expectativas relacionadas con los patrones de subsistencia en los dominios del Tawantinsuyu y de referencias en los registros etnohistóricos (Planella 1988). Estos sugieren un aumento en la importancia del maíz y la agricultura con sistemas de canales de regadío, visualizada por los españoles en el siglo XVI y por la existencia de "collcas" en algunas instalaciones defensivas incas (Cerro La Compañía) que reflejan la importancia del almacenaje de productos. La documentación histórica deja fuera de discusión que a mediados del siglo XVI los cultivos de maíz estaban fuertemente arraigados entre los naturales de la región central y que su consumo era generalizado. De ello se infiere que este recurso de subsistencia, así como muchos otros, provenía del desarrollo hortícola y/o agrícola logrado por las poblaciones indígenas en épocas anteriores.

\section{Materiales y Método}

El área de estudio está comprendida entre las cuencas de los ríos Maipo-Mapocho y Cachapoal $\left(33^{\circ}\right.$ a $34^{\circ} 15^{\prime}$ Lat. Sur) e incluye muestras de recursos y de individuos rescatados de sitios arqueológicos de la costa, valles de la cordillera de la costa y valle central (Figura 1).

En el caso de los recursos ${ }^{3}$, se analizó un total de 42 muestras (Tabla 1). Los vegetales provienen de colectas actuales porque los recuperados de sitios arqueológicos están carbonizados, y abarcan las especies comestibles silvestres y cultivadas potencialmente más importantes para la población prehispana, algunos con ejemplares de costa, valle y cordillera. La fauna, en su mayoría, proviene de excavaciones arqueológicas, salvo el caso de los moluscos -ya que en los sitios arqueológicos sólo se preservan las conchas- y algunos peces, para los que no se disponía de la cantidad suficiente en las colecciones arqueológicas. La fauna lacustre tiene ejemplares de sitios arqueológicos próximos a una laguna costera y una en el valle y el guanaco (Lama guanicoe) de sitios arqueológicos de costa, valle y cordillera.

En el caso de los individuos, la estrategia de selección fue guiada por el objetivo de reunir un número balanceado por contexto cultural y ambiente (costa e interior) ${ }^{4}$, a excepción de los conjuntos CAI, para los que no se dispone de muestras de la costa, e Inca debido a la escasa presencia que tuvo el Tawantinsuyu en el litoral. En la muestra existe una presencia mínima de individuos Bato de interior que se debe a la escasez de ellos en las colecciones. Dentro de cada conjunto cultural/ambiental se escogió, en los casos que fue posible, un sitio prioritario del que se analizaron cuatro a seis individuos que representaran una población de un mismo lugar y un conjunto de individuos de sitios di- 
Tabla 1. Datos generales y resultados isotópicos de los recursos marinos, lacustres y terrestres analizados para Chile central. General information and isotope data for marine, fresh water and terrestrial resources analyzed for Central Chile.

\begin{tabular}{|c|c|c|c|c|c|c|c|c|}
\hline Especie & $\begin{array}{l}\text { Nombre } \\
\text { común }\end{array}$ & Región & Contexto & $\begin{array}{l}\text { Sitio/ } \\
\text { Localidad }\end{array}$ & $\begin{array}{l}\text { Parte } \\
\text { anatómica }\end{array}$ & $\begin{array}{c}\text { Id } \\
\text { USF\# }\end{array}$ & $\begin{array}{c}\delta^{13} \mathrm{C} \\
\% 0\end{array}$ & $\begin{array}{c}\delta^{15} \mathrm{~N} \\
\% o\end{array}$ \\
\hline \multicolumn{9}{|l|}{ Fauna lacustre } \\
\hline Myocastor coipus & coipo & costa & Bato & Arévalo-2 & maxilar & 7977 & $-22,3$ & 5,2 \\
\hline Caudiverbera caudiverbera & rana & costa & Aconcagua & TV1 & 1 hueso & 7978 & $-23,4$ & 8,9 \\
\hline Myocastor coipus & coipo & valle & PAT & Cuchipuy & maxilar & 7979 & $-16,0$ & 2,1 \\
\hline \multicolumn{9}{|l|}{ Fauna marina } \\
\hline Otaria sp. & lobo marino & costa & Bato & Arévalo-2 & falange (segunda) & 7981 & $-11,7$ & 20,2 \\
\hline Tegula atra & caracol negro & costa & Actual & Maitencillo & Animal & 7982 & $-13,2$ & 15,2 \\
\hline Choromytilus chorus & choro zapato & costa & Actual & Maitencillo & Animal & 7983 & $-15,9$ & 17,6 \\
\hline Mesodesma donacium & macha & costa & Actual & Maitencillo & Animal & 7984 & $-17,2$ & 14,2 \\
\hline Concholepas concholepas & loco & costa & Actual & Maitencillo & Animal & 8268 & $-15,0$ & 16,8 \\
\hline Cilus gilberti & corvina & costa & Actual & San Antonio & Cráneo & 7985 & $-13,3$ & 18,2 \\
\hline Aplodactylus punctatus & jerguilla & costa & Actual & San Antonio & Cráneo & 7986 & $-15,5$ & 16,0 \\
\hline Trachurus symmetricus & jurel & costa & Actual & San Antonio & Cráneo & 7987 & $-13,6$ & 18,5 \\
\hline Merluccius gayi & merluza & costa & Actual & San Antonio & Cráneo & 7988 & $-11,4$ & 17,9 \\
\hline Micropogonia furnieri & roncador & costa & Aconcagua & L. Matanzas & hiomandibular & 7990 & $-14,9$ & 12,7 \\
\hline \multicolumn{9}{|l|}{ Fauna terrestre } \\
\hline Lama guanicoe & guanaco & cordillera & Aconcagua & Escobarinos & falange (primera) & 7991 & $-19,3$ & 5,2 \\
\hline Lama guanicoe & guanaco & cordillera & Arcaico & Queltehues & húmero & 8543 & $-18,6$ & 4,1 \\
\hline Lama guanicoe & guanaco & costa & Aconcagua & TV-1 & falange & 7992 & $-19,7$ & 6,4 \\
\hline Lama guanicoe & guanaco & costa & Bato & Arévalo-2 & tibia & 8541 & $-19,1$ & 4,0 \\
\hline Lama guanicoe & guanaco & valle & Bato & La Palma & radio-ulna & 7993 & $-20,2$ & 5,4 \\
\hline Lama guanicoe & guanaco & valle & Llolleo & La Granja & metapodio & 8542 & $-19,9$ & 4,7 \\
\hline \multicolumn{9}{|l|}{ Vegetal marino } \\
\hline Durvillea antartica & cochayuyo & costa & Actual & Con Con & tallo & 8015 & $-17,3$ & \\
\hline Porphyra columbina & luche & costa & Actual & Maitencillo & hojas & 8016 & $-14,0$ & \\
\hline \multicolumn{9}{|l|}{ Vegetal silvestre } \\
\hline Puyasp. & chagual & cord. costa & Actual & Mercado & corazón & 7995 & $-21,0$ & \\
\hline Nasella chilensis & paja & cordillera & Actual & C. Farellones & espiga, semillas & 7994 & $-22,3$ & \\
\hline Peuтиs boldus & boldo & cordillera & Actual & Arrayán & fruto & 8000 & $-26,7$ & \\
\hline Cryptocaria alba & peumo & cordillera & Actual & Arrayán & fruto & 8001 & $-23,5$ & \\
\hline Brodiaea porrifolia & cebolleta & costa & Actual & Maitencillo & bulbos & 7996 & $-27,5$ & \\
\hline Schinus latifolius & molle & costa & Actual & Maitencillo & fruto & 7997 & $-27,3$ & \\
\hline Jubaea chilensis & palma & costa & Actual & Viña del Mar & fruto & 7998 & $-24,4$ & \\
\hline Cryptocaria alba & peumo & costa & Actual & Maitencillo & fruto & 7999 & $-25,6$ & \\
\hline Prosopis chilensis & algarrobo & valle & Actual & Antumapu & vaina, semillas & 8002 & $-26,7$ & \\
\hline Luma apiculata & arrayán & valle & Actual & Santiago & fruto & 8003 & $-30,4$ & \\
\hline Peumus boldus & boldo & valle & Actual & VI Región & fruto & 8004 & $-28,7$ & \\
\hline Madia sativa & madi & valle & Actual & Quincanque & flor & 8005 & $-30,5$ & \\
\hline Aristotelia chilensis & maqui & valle & Actual & Linares & fruto & 8006 & $-29,2$ & \\
\hline Cryptocaria alba & peumo & valle & Actual & Santiago & fruto & 8007 & $-28,1$ & \\
\hline \multicolumn{9}{|l|}{ Vegetal cultivado } \\
\hline Solanum maglia & papacimarrona & costa & Actual & Maitencillo & bulbo & 8008 & $-24,7$ & \\
\hline Lagenaria sp. & calabaza & valle & Actual & Chada & semillas & 8009 & $-27,2$ & \\
\hline Zea mays & maíz curagua & valle & Actual & VI Región & granos & 8010 & $-11,2$ & \\
\hline Phaseolus lunatus & pallar flor blanca & valle & Actual & VI Región & semillas & 8011 & $-25,7$ & \\
\hline Solanum tuberosum & papa & valle & Actual & Santiago & bulbo & 8012 & $-29,3$ & \\
\hline Chenopodium quinoa & quínoa & valle & Actual & Paredones & semillas & 8013 & $-26,1$ & \\
\hline Cucurbita sp. & zapallo hoyo & valle & Actual & VI Región & semillas & 8014 & $-26,6$ & \\
\hline
\end{tabular}




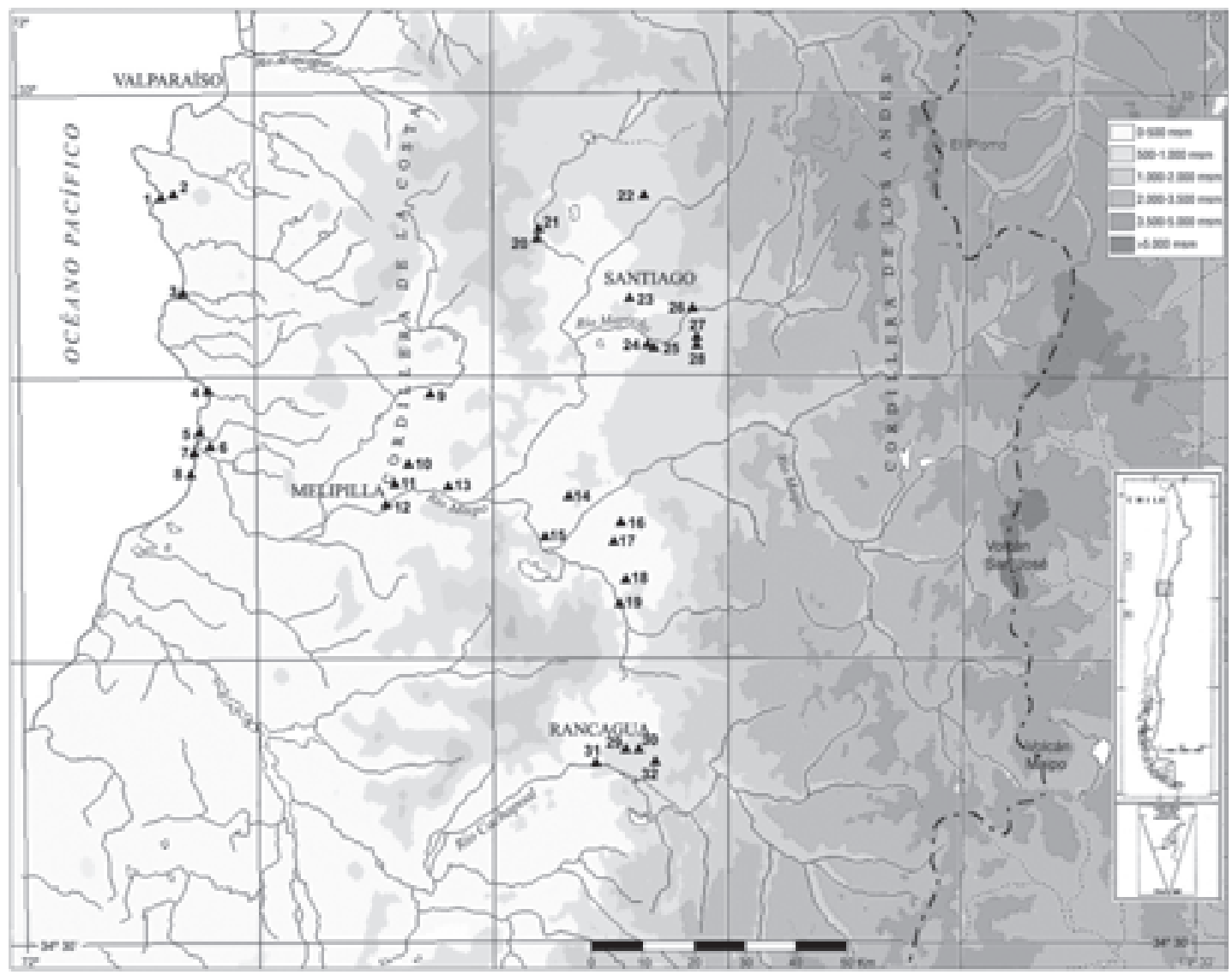

Figura 1. Mapa de Chile central con los sitios arqueológicos de donde proceden las muestras humanas analizadas. (1) El Trébol Sureste $N^{\circ}$ 11, (2) Cancha de Golf $N^{\circ}$ 1, (3) Los Puquios, (4) Laguna El Peral-C, (5) Arévalo-2, (6) Tejas Verdes 4 y 5, (7) Santo Domingo 1, (8) Las Brisas 10-14, (9) María Pinto, (10) Pomaire, (11) Villa Galilea, (12) El Bajo de Melipilla, (13) Chiñigüe 2, (14) Lonquén, (15) Las Mercedes, (16) Villa Virginia, (17) Nos, (18) Hospital 8-9, (19) Las Pataguas, (20) El Valle Chicauma, (21) El Almendral, (22) Valle Verde, (23) Las Tinajas de Quilicura, (24) Carrascal 1 y 3, (25) Línea 5 Metro, (26) El Mercurio, (27) Country Club, (28) Lenka Franulic, (29) Las Coloradas, (30) Alto Jahuel, (31) La Granja y Paso Agrícola, (32) Condomino Los Llanos.

Map of Central Chile showing the location of archaeological sites from which the analyzed human bones samples were taken. (1) El Trébol Sureste $\mathrm{N}^{\circ}$ 11, (2) Cancha de Golf $\mathrm{N}^{\circ}$ 1, (3) Los Puquios, (4) Laguna El Peral-C, (5) Arévalo-2, (6) Tejas Verdes 4 y 5, (7) Santo Domingo 1, (8) Las Brisas 10-14, (9) María Pinto, (10) Pomaire, (11) Villa Galilea, (12) El Bajo de Melipilla, (13) Chiñigüe 2, (14) Lonquén, (15) Las Mercedes, (16) Villa Virginia, (17) Nos, (18) Hospital 8-9, (19) Las Pataguas, (20) El Valle Chicauma, (21) El Almendral, (22) Valle Verde, (23) Las Tinajas de Quilicura, (24) Carrascal 1 y 3, (25) Línea 5 Metro, (26) El Mercurio, (27) Country Club, (28) Lenka Franulic, (29) Las Coloradas, (30) Alto Jahuel, (31) La Granja y Paso Agrícola, (32) Condomino Los Llanos.

versos para abrir el espectro a un número mayor de procedencias. En el caso del sitio El Mercurio se seleccionaron 10 muestras debido a la mala conservación de los restos óseos y la particular importancia que tiene este sitio en los estudios sobre el complejo cultural Llolleo.

En este estudio se usan muestras de hueso de un total de 92 individuos y una submuestra de dientes de 26 de ellos (Tabla 2). En todos los casos se usó el tercer molar (m3), cuyo esmalte se forma en promedio entre los 9 y 12 años de edad, el que fue escogido por ser el último diente en desarrollarse, con el supuesto que representa la dieta en la residencia antes del paso a la adultez.

Se seleccionaron sólo individuos adultos, para evitar sesgos por dietas diferenciadas según edad, entre los que buscamos el mayor balance posible entre masculinos y femeninos. Si bien se privilegió los que tuvieran buen respaldo de información arqueológica, en muchos casos se tuvo que recurir a colecciones o a rescates que no cuentan con suficientes datos de la excavación del individuo. 
Todos los individuos cuentan, al menos, con una asignación a un contexto cultural por asociación a elementos diagnósticos y/o por fechas del sitio. Algunos de ellos tienen, además, una asignación cronológica más precisa a través del fechado de algún elemento cultural en asociación directa (vasija de la ofrenda), o por fechado AMS directo (Tabla 3 ).

En la obtención de la muestra se buscó ser lo menos destructivo posible escogiendo áreas de los huesos que no tuvieran información morfológica relevante (inserciones musculares, patologías) y en algunos casos se prefirió usar fragmentos para no perjudicar especímenes más completos poniendo siempre énfasis en la conservación del material patrimonial. Si bien no existe diferencia significativa de las señales isotópicas entre los diferentes huesos de un individuo se privilegió el uso del fémur u otro hueso largo por su mayor aporte de colágeno. En los casos en que no se dispuso de ellos, se utilizó otro hueso (Tabla 2). La muestra de hueso se cortó con un disco de diamante (Dremmel \# 545 de $22 \mathrm{~mm}$ de diámetro y $0,5 \mathrm{~mm}$ de espesor) montado en un taladro de mano de velocidad variable. Se extrajeron entre 1 y $3 \mathrm{gr}$ de hueso para los análisis.

Las muestras fueron preparadas para los análisis isotópicos en el laboratorio de arqueología de la Universidad de South Florida, campus Tampa y recibieron un número de identificación para el colágeno (USF-c), apatita (USF-a) y esmalte dental (USF-e). Todo el proceso estuvo a cargo del coautor Dr. Robert H. Tykot. Las muestras fueron preparadas siguiendo los protocolos para obtención de colágeno y de apatita del laboratorio de la USF (Tykot 2004). En los procedimientos para separar el colágeno se obtuvieron seudomorfos, los que son un indicador visual de la integridad de la muestra. La integridad fue evaluada también a través del porcentaje de colágeno obtenido del hueso (superior a 1\%). En el caso de la apatita y del esmalte dental se utilizaron procedimientos para remover el carbono no biogénico sin alterar los valores del carbono biogénico, con lo cual se eliminan las contaminaciones por procesos diagenéticos. Las muestras luego fueron analizadas en equipos de espectroscopia de masa para isótopos estables de la

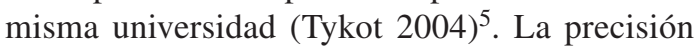
analítica de la espectrometría de masas para la razón isotópica es $\pm 0,1 \%$ o para $\delta^{13} \mathrm{C}$ y $\pm 0,2 \%$ o para $\delta^{15} \mathrm{~N}$.

\section{Discusión de los Resultados}

\section{Recursos}

En el gráfico de la Figura 2 se muestran los rangos de los valores $\delta^{13} \mathrm{C}$ y $\delta^{15} \mathrm{~N}$ de las especies de plantas y animales de importancia dietética de Chile central analizados, agrupados por tipos de recurso (para el detalle de los valores isotópicos de los recursos ver Tabla 1).

En el caso de las plantas, el $\delta^{13} \mathrm{C}$ es el medido en las muestras de Chile central y el $\delta^{15} \mathrm{~N}$ es un valor teórico. Los valores $\delta^{13} \mathrm{C}$ obtenidos se mueven dentro de los rangos de plantas $\mathrm{C} 3, \mathrm{C} 4$ y marinas en otras regiones del mundo. Las plantas $\mathrm{C} 3$ son las que presentan valores más bajos de carbono; las algas presentan valores de carbono intermedios y valores de $\mathrm{N}$ con un rango muy amplio, mientras que el maíz, único espécimen $\mathrm{C} 4$ de la muestra, tiene los valores de $\mathrm{C}$ más enriquecidos.

La fauna de agua dulce (coipo y rana) aparece segregada de la continental (guanacos) y de toda la marina (moluscos, peces y mamíferos). Se obtuvo

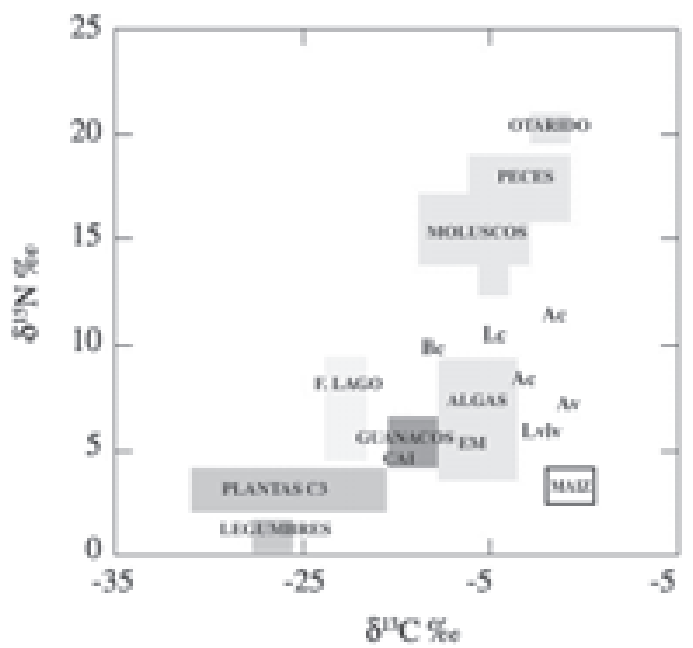

Figura 2. Rangos de los valores $\delta^{13} \mathrm{C}$ y $\delta^{15} \mathrm{~N}$ del colágeno de los recursos locales y promedios de los valores $\delta^{13} \mathrm{C}$ y $\delta^{15} \mathrm{~N}$ del colágeno de los individuos de los contextos culturales estudiados: Comunidades Alfareras Iniciales (CAI), Bato costa (Bc), Llolleo costa (Lc), Llolleo valle (Lv), Llolleo del sitio El Mercurio (EM), Aconcagua costa (Ac), Aconcagua valle (Av), Inca valle (Iv). Collagen $\delta^{13} \mathrm{C}$ and $\delta^{15} \mathrm{~N}$ ranges of marine and terrestrial resources for Central Chile and mean collagen $\delta^{13} \mathrm{C}$ and $\delta^{15} \mathrm{~N}$ values of human bones samples according to cultural contexts: Comunidades Alfareras Iniciales (Initial Potter Communities) (CAI), Bato coast (Bc), Llolleo coast ( $\mathrm{Lc})$, Llolleo valley (Lv), Llolleo from site El Mercurio (EM), Aconcagua coast (Ac), Aconcagua valley (Av), Inca valley (Iv). 


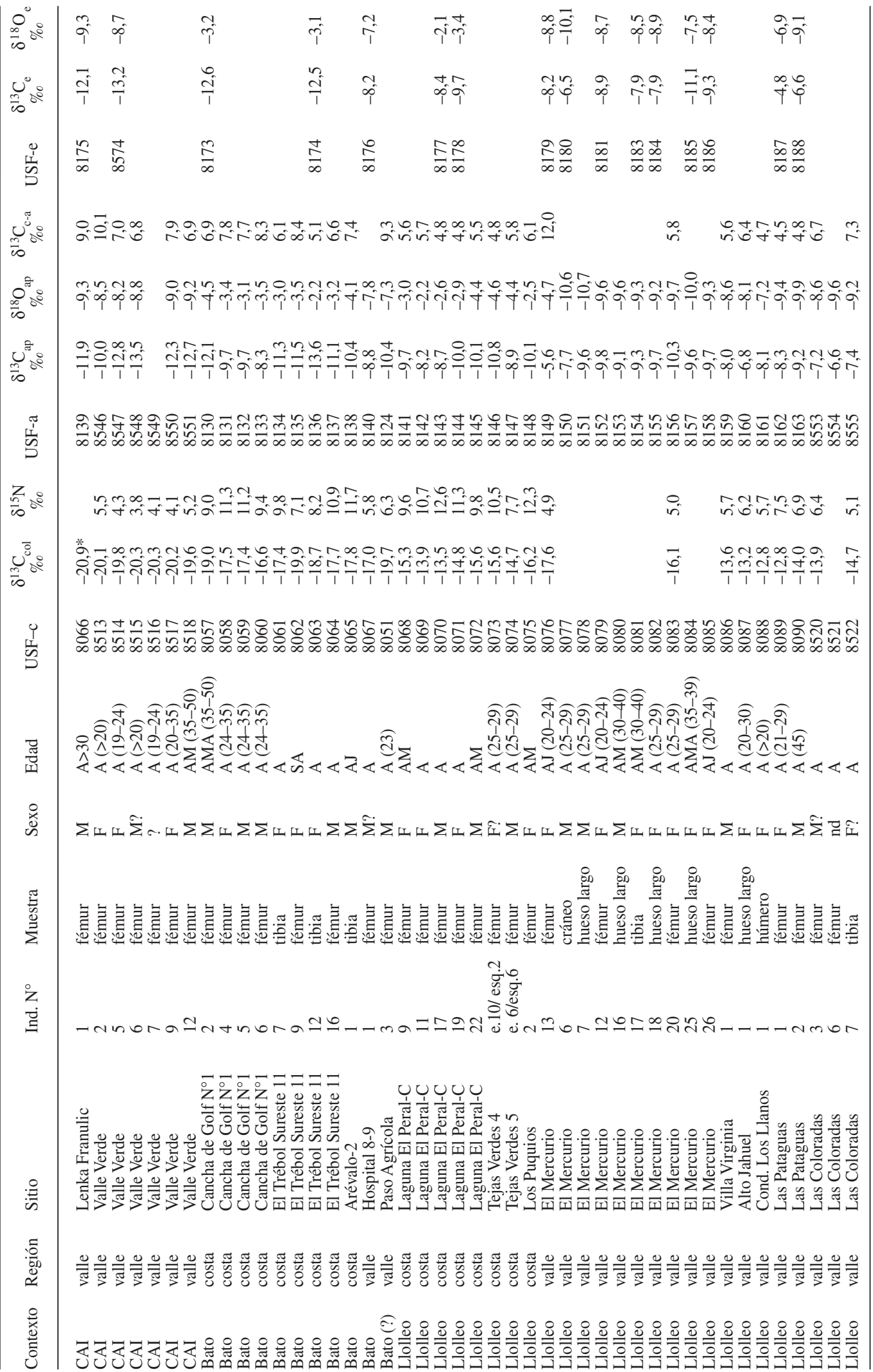




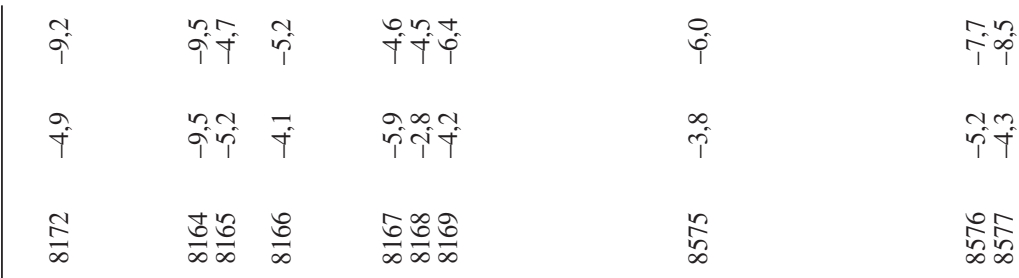

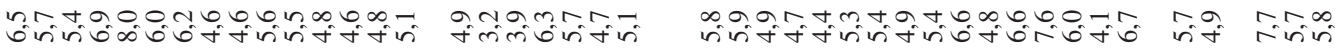

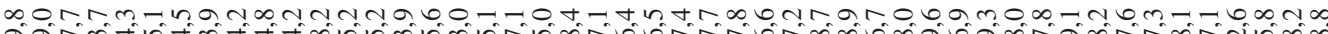

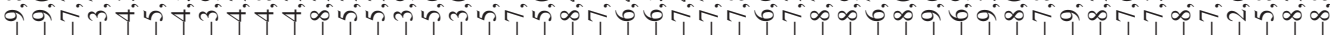

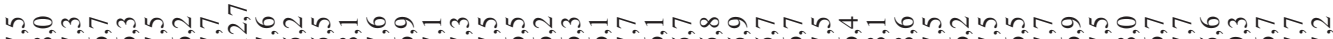

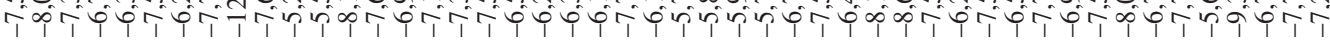

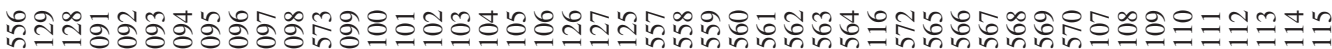

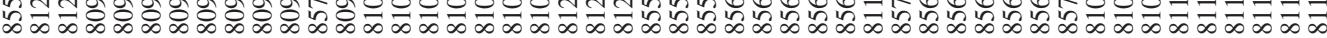

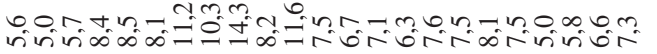

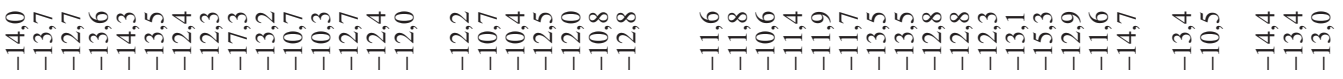

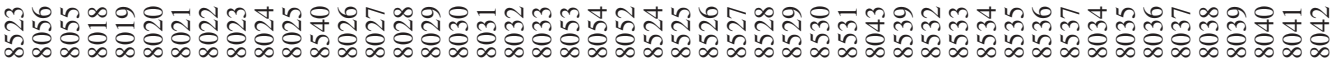

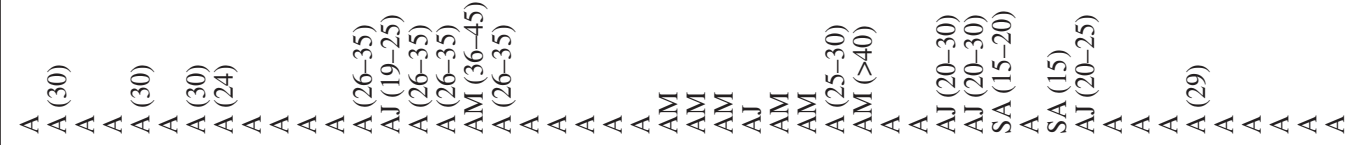

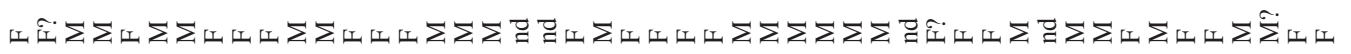
总

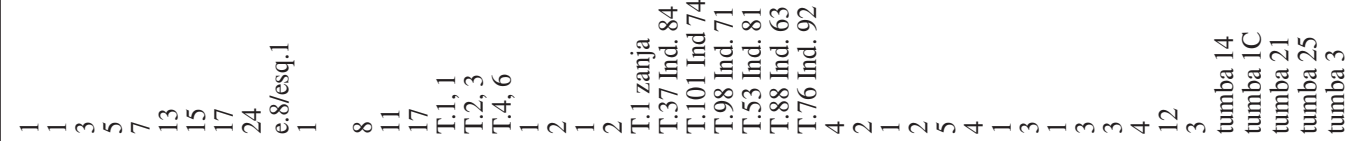

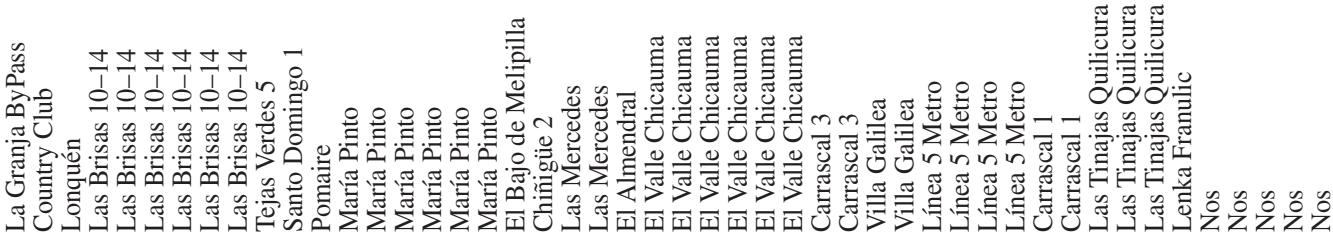

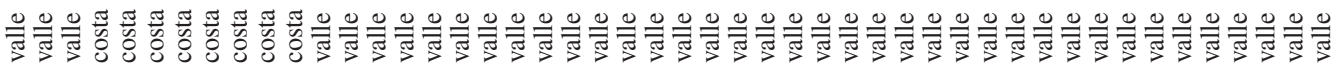

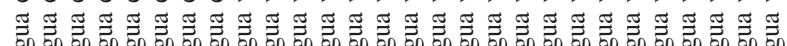


Tabla 3. Fechados AMS ${ }^{14} \mathrm{C}$ y TL de individuos analizados y/o de ofrendas asociadas. $A M S{ }^{14} C$ and TL dates of analyzed human bones samples and/or of associated offerings.

\begin{tabular}{|c|c|c|c|c|c|}
\hline Sitio & Ind. $\mathrm{N}^{\circ}$ & Contexto & Región & * & Fechas** \\
\hline Valle Verde & 6 & CAI & valle & + & $2180 \pm 40$ a.p., Beta-213488, 370 - 110 cal. a.C. \\
\hline Valle Verde & 9 & CAI & valle & + & $2220 \pm 40$ a.p., Beta-211328, 390 - 180 cal. a.C. \\
\hline Lenka Franulic & 1 & CAI & valle & + & 1997 \pm 56 a.p., AA63824, 170 a.C. a 130 cal. d.C. \\
\hline Cancha de Golf $N^{\circ} 1$ & 5 & Bato & costa & + & $1405 \pm 47$ a.p., $A A 63823,550-690$ cal. d.C. $^{1}$ \\
\hline Hospital 8-9 & 1 & Bato & valle & + & $1380 \pm 46$ a.p., AA68050, 575 - 766 cal. d.C. \\
\hline Paso Agrícola & 3 & Bato (?) & valle & + & 1234 \pm 52 a.p., AA64986, 660 - 900 cal. d.C. \\
\hline Laguna El Peral-C & 17 & Llolleo & costa & - & TL, vasija, $590 \pm 140$ d.C. (Falabella y Planella 1991) \\
\hline Tejas Verdes 4 & e. $10 /$ esq. 2 & Llolleo & costa & + & $1085 \pm 33$ a.p., AA64988, $890-1020$ cal. d.C. ${ }^{2}$ \\
\hline El Mercurio & 13 & Llolleo & valle & - & TL, vasija ofrenda, $1080 \pm 90$ d.C. (Falabella 2000a) \\
\hline El Mercurio & 20 & Llolleo & valle & - & TL, vasija ofrenda, $935 \pm 100$ d.C. (Falabella 2000a) \\
\hline Las Pataguas & 2 & Llolleo & valle & - & TL, vasija ofrenda, $885 \pm 80$ d.C. (UCTL 1710) \\
\hline Lonquén & 3 & Llolleo & valle & + & 1091 \pm 46 a.p., AA68048, $784-1025$ cal. d.C. \\
\hline Country Club & 1 & Llolleo & valle & + & $1169 \pm 46$ a.p., AA68049, 719 - 983 cal. d.C. \\
\hline Las Brisas 10-14 & 5 & Aconcagua & costa & - & 1297-1699 cal. d.C., carbón (Ciprés Consultores 2003) \\
\hline Las Brisas 10-14 & 7 & Aconcagua & costa & - & 1295-1526 cal. d.C., carbón (Ciprés Consultores 2003) \\
\hline El Almendral RML 002 & T.1 zanja & Aconcagua & valle & + & 467 444 a.p., AA68047, 1328-1615 cal. d.C. \\
\hline Valle Chicauma (RML 004) & T.37 Ind. 84 & Aconcagua & valle & + & 1415-1440 cal d.C. (1 sigma, Sánchez 1995) \\
\hline Valle Chicauma (RML 004) & T.53 Ind. 81 & Aconcagua & valle & - & TL 975 \pm 100 d.C. (Sánchez 1995) \\
\hline Las Mercedes & 2 & Aconcagua & valle & + & $602 \pm 33$ a.p., AA64987, $1290-1410$ cal. d.C. \\
\hline Línea 5 Metro & 5 & Inca & valle & - & TL $1495 \pm 50$ d.C., TL $1405 \pm 60$ d.C. (Reyes 2003) \\
\hline Línea 5 Metro & 4 & Inca & valle & - & TL $1470 \pm 50$ d.C., TL $1485 \pm 55$ d.C. (Reyes 2003 ) \\
\hline Línea 5 Metro & 1 & Inca & valle & - & TL $1485 \pm 55$ d.C. (Reyes 2003$)$ \\
\hline Línea 5 Metro & 3 & Inca & valle & - & TL $1475 \pm 50$ d.C. (Reyes 2003) \\
\hline
\end{tabular}

+ Fecha AMS ${ }^{14} \mathrm{C}$ del colágeno del hueso, calibrada con 2 sigmas, OxCal v.3.10, Intcal04 (Reimer et al. 2004).

- Fecha de ofrenda asociada.

\footnotetext{
**

${ }^{1}$ Fecha calibrada para 30\% de dieta marina (Reimer et al. 2004): AA63823, 659 - 866 cal d.C.

${ }^{2}$ Fecha calibrada para 30\% de dieta marina (Reimer et al. 2004): AA64988, 1.000 - 1.155 cal. d.C.
}

un valor muy diferente $\left(\delta^{13} \mathrm{C}-16,0 \%\right.$ o, $\delta^{15} \mathrm{~N} 2,1 \%$ o para un coipo de agua dulce del sitio Cuchipuy en los márgenes de la laguna de Tagua Tagua (valle de la cordillera de la costa en la VI región) y que tiene una tendencia distinta a la comúnmente esperada en los organismos dulceacuícolas, valores altos en nitrógeno y empobrecidos en carbono. La explicación que damos a esta diferencia es que los organismos de agua dulce se comportan con valores muy disímiles en distintos ambientes, hecho que ha sido constatado en diversos casos de Europa y Norteamérica (Little y Schoeninger 1995; van der Merwe et al. 2003) ${ }^{6}$.

El guanaco, Lama guanicoe, es la única especie que analizamos de fauna terrestre local $(n=6)$. Estos ejemplares dieron valores dentro del rango de lo esperado (Tabla 1), más enriquecido en $\mathrm{N}$ y levemente enriquecido en $\mathrm{C}$ en relación a su fuen- te alimenticia (pastos C3). Los organismos marinos se muestran progresivamente enriquecidos tanto en $\mathrm{N}$ como en $\mathrm{C}$ de acuerdo a sus posiciones en la cadena trófica: moluscos y peces herbívoros, luego los peces carnívoros y por último el ejemplar de otárido, como mamífero marino.

El número de recursos que analizamos en nuestro trabajo es limitado y, a excepción de algunas plantas y de los guanacos, sólo se analizó un ejemplar de cada especie. Nos interesa hacer notar sin embargo que estos valores se insertan dentro de los rangos obtenidos en muestreos intensivos de plantas y animales que se han realizado en otras regiones, como es el publicado por Tieszen y Chapman (1992) en el norte de Chile en el cual se analizó una cantidad importante de plantas y fauna marina de varias especies registradas en nuestros sitios arqueológicos. 
En síntesis, los valores $\delta^{13} \mathrm{C}$ y $\delta^{15} \mathrm{~N}$ obtenidos de nuestros recursos locales potencialmente alimenticios coinciden con los valores medidos en fauna y vegetales de otras regiones y segregan tipos de recursos, lo que nos permite confiablemente establecer una distinción para los conjuntos de vegetales C3, C4, algas, fauna lacustre litoral, herbívoros terrestres (guanaco), moluscos, peces y mamíferos marinos, como referentes para la interpretación dietética.

\section{Poblaciones alfareras prehispanas}

En general los resultados revelan coherencia interna por contexto cultural y ambiente y diferencia entre contextos y ambientes diferentes (Figura 2 y 3 , Tablas 2 y 4). La diferencia entre los promedios isotópicos de los grupos CAI, Bato, Llolleo, Aconcagua e Inca es estadísticamente significati$\mathrm{va}^{7}$, señalando que la dieta es un elemento cultural distintivo de las poblaciones prehispanas de Chile central. Existen asimismo diferencias importantes entre los individuos de costa y valle de algunos de estos contextos.

\section{Comunidades Alfareras Iniciales}

La muestra de Comunidades Alfareras Iniciales analizada se compone de siete individuos que provienen de dos sitios arqueológicos, Lenka Franulic y Valle Verde, ambos en la cuenca de Santiago (Tabla 2). Es el conjunto que presenta los valores isotópicos más bajos, los que coinciden con los de los guanacos analizados. Están marcando una dieta basada en vegetales $\mathrm{C} 3$ con un valor $\delta^{15} \mathrm{~N}$ que indica escaso o nulo aporte de proteína animal. El espaciamiento entre el colágeno y la apatita de 7,6 es una evidencia adicional del énfasis vegetariano en la alimentación.

Desde el punto de vista cultural, se trata de los grupos que articulan las sociedades del período Arcaico Final y el período Alfarero Temprano en la zona. Con los escasos antecedentes arqueológicos de sitios CAI en el valle, en la literatura se ha planteado que mantienen estrategias de caza y recolección (Sanhueza y Falabella 2003). Se han encontrado escasos especímenes de plantas domésticas asociados a estos contextos, entre ellos, granos de quínoa (Chenopodium quinoa) en el componente CAI del sitio Lonquén y probables gránulos de almidón de la misma especie en un molino del sitio Lenka Franulic (Planella et al. 2006). También se ha registrado quínoa en el sitio Las Morrenas 1 del período Arcaico Tardío de la precordillera de la cuenca del río Maipo con fechas AMS de 3.250 a 2.980 a.p. avalando la presencia de este cultígeno en Chile central antes de la configuración de las Comunidades Alfareras Iniciales como tales (Planella et al. 2005).

Quizás la pregunta más importante que surge de los resultados isotópicos es cómo se podrían obtener las proteínas necesarias para el organismo en una dieta con perfiles tan vegetarianos. La respuesta debe estar en plantas de alto valor proteico. Con los antecedentes disponibles, las fuentes posibles son alguna leguminosa silvestre y/o quínoa (Chenopodium quinoa) cuyos frutos no sólo son ricos en proteínas (11 a 21\%) sino que contienen

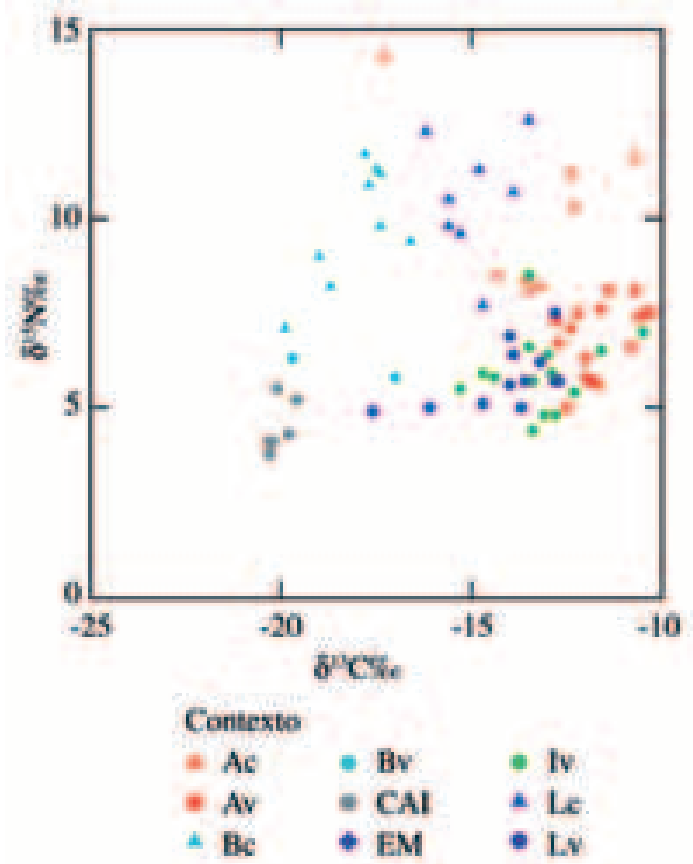

Figura 3. Valores $\delta^{13} \mathrm{C}$ y $\delta^{15} \mathrm{~N}$ por mil del colágeno de los individuos analizados, que muestran variación en la importancia de los recursos marinos y plantas $\mathrm{C} 4$ entre las poblaciones de la costa e interior de Chile central: Comunidades Alfareras Iniciales (CAI), Bato costa $(\mathrm{Bc})$, Bato valle $(\mathrm{Bv})$, Llolleo costa (Lc), Llolleo valle (Lv), Llolleo del sitio El Mercurio (EM), Aconcagua costa (Ac), Aconcagua valle (Av), Inca valle (Iv). Collagen $\delta^{13} C$ and $\delta^{15} N$ per mil values in analyzed human samples, showing variation in importance of seafood and $C 4$ plants in coastal and inland populations from Central Chile: Comunidades Alfareras Iniciales (Initial Potter Communities) (CAI), Bato coast $(\mathrm{Bc})$, Bato valley $(\mathrm{Bv})$, Llolleo coast $(\mathrm{Lc})$, Llolleo valley (Lv), Llolleo from site El Mercurio (EM), Aconcagua coast (Ac), Aconcagua valley (Av), Inca valley (Iv). 
Tabla 4. Promedio (prom.) y desviación estándar (D.S.) de los datos isotópicos para los contextos culturales estudiados. Mean (prom.) isotope values and standard deviation (D.S.) for each cultural context.

\begin{tabular}{|c|c|c|c|c|c|c|c|c|c|}
\hline Contexto & $\mathrm{n}$ & & $\delta^{13} \mathrm{C}_{\mathrm{col}} \% o$ & $\delta^{15} \mathrm{~N} \%$ & $\delta^{13} \mathrm{C}_{\mathrm{ap}} \%$ & $\delta^{18} \mathrm{O}_{\text {ap }} \% o$ & $\delta^{13} \mathrm{C} \mathrm{c-a} \%$ & $\delta^{13} \mathrm{C}_{\mathrm{e}} \% 0$ & $\delta^{18} \mathrm{O}_{\mathrm{e}} \% 0$ \\
\hline \multirow[t]{2}{*}{ CAI valle } & \multirow[t]{2}{*}{7} & prom. & $-20,1$ & 4,5 & $-12,2$ & $-8,8$ & 7,7 & $-12,7$ & $-9,0$ \\
\hline & & D.S. & 0,3 & 0,7 & 1,2 & 0,4 & 1,4 & 0,8 & 0,4 \\
\hline \multirow[t]{2}{*}{ Bato costa } & \multirow[t]{2}{*}{9} & prom. & $-18,0$ & 9,8 & $-10,9$ & $-3,4$ & 7,1 & $-12,6$ & $-3,2$ \\
\hline & & D.S. & 1,0 & 1,6 & 1,5 & 0,7 & 1,1 & 0,1 & 0,1 \\
\hline \multirow[t]{2}{*}{ Bato valle } & \multirow[t]{2}{*}{2} & prom. & $-19,7$ & 6,3 & $-9,6$ & $-7,6$ & 10,1 & $-8,2$ & $-7,2$ \\
\hline & & D.S. & & & 1,1 & 0,4 & & & \\
\hline \multirow[t]{2}{*}{ Llolleo costa } & \multirow[t]{2}{*}{8} & prom. & $-15,0$ & 10,6 & $-9,6$ & $-3,3$ & 5,4 & $-9,1$ & $-2,8$ \\
\hline & & D.S. & 0,9 & 1,6 & 0,9 & 1,0 & 0,5 & 0,9 & 0,9 \\
\hline \multirow{2}{*}{$\begin{array}{l}\text { Llolleo valle } \\
\text { (El Mercurio) }\end{array}$} & \multirow[t]{2}{*}{10} & prom. & $-16,9$ & 5,0 & $-9,0$ & $-9,3$ & 7,8 & $-8,5$ & $-8,7$ \\
\hline & & D.S. & 1,1 & 0,1 & 1,4 & 1,7 & 4,4 & 1,4 & 0,8 \\
\hline \multirow{2}{*}{$\begin{array}{l}\text { Llolleo valle } \\
\text { (Otros sitios) }\end{array}$} & \multirow[t]{2}{*}{11} & prom. & $-13,5$ & 6,0 & $-7,7$ & $-8,8$ & 5,8 & $-5,4$ & $-8,4$ \\
\hline & & D.S. & 0,7 & 0,8 & 0,7 & 0,9 & 0,9 & 1,0 & 1,3 \\
\hline \multirow{2}{*}{$\begin{array}{l}\text { Aconcagua costa } \\
\text { (a) }\end{array}$} & \multirow[t]{2}{*}{4} & prom. & $-13,7$ & 8,3 & $-7,0$ & $-4,5$ & 6,6 & $-4,1$ & $-5,2$ \\
\hline & & D.S. & 0,5 & 0,2 & 0,6 & 0,6 & 1,1 & & \\
\hline \multirow{2}{*}{$\begin{array}{l}\text { Aconcagua costa } \\
\text { (b) }\end{array}$} & \multirow[t]{2}{*}{3} & prom. & $-11,8$ & 11,0 & $-6,4$ & $-4,2$ & 5,3 & $-5,2$ & $-4,7$ \\
\hline & & D.S. & 1,0 & 0,7 & 1,3 & 0,3 & 1,1 & & \\
\hline \multirow[t]{2}{*}{ Aconcagua valle } & \multirow[t]{2}{*}{19} & prom. & $-11,6$ & 6,8 & $-6,6$ & $-6,6$ & 4,9 & $-4,2$ & $-5,4$ \\
\hline & & D.S. & 0,8 & 1,0 & 0,8 & 1,7 & 0,8 & 1,3 & 1,0 \\
\hline \multirow[t]{2}{*}{ Inca valle } & \multirow[t]{2}{*}{17} & prom. & $-13,1$ & 5,9 & $-7,4$ & $-7,6$ & 5,9 & $-4,7$ & $-8,1$ \\
\hline & & D.S. & 1,2 & 1,0 & 0,9 & 1,6 & 1,0 & 0,6 & 0,5 \\
\hline
\end{tabular}

una combinación muy adecuada de aminoácidos para la nutrición humana. El consumo de leguminosas reduce, además, las señales $\delta^{15} \mathrm{~N}$ en el consumidor, lo que podría estar incidiendo en los índices tan empobrecidos de $\mathrm{N}$ y oscureciendo las señales de un consumo reducido de carne. Lamentablemente los isótopos no discriminan entre plantas C3 cultivadas y silvestres como para tener mayor precisión.

De ser efectivo un patrón dietético con menor ingesta de carne animal y algo de cultivos, significaría un cambio respecto al período Arcaico anterior al que se deben buscar sus motivos y consecuencias. La posibilidad de que la quínoa haya sido más importante que lo reflejado por los escasos restos arqueobotánicos en los hábitos alimentarios de las CAI, implicaría que dependieron en algún grado del manejo de cultivos, lo que conlleva diferencias en las formas de relacionarse con la naturaleza y decisiones sobre el uso de sus territorios que pueden comprometer cambios de distinta magnitud respecto a los sistemas de vida anteriores. Las señales $\delta^{18} \mathrm{O}$ de todos los individuos (Tabla 2) están dentro del rango que consideramos propio del valle central, lo que estaría sugiriendo un sistema de asentamiento sólo en el interior, diferente al de algunas poblaciones móviles del período Arcaico.

No se aprecian diferencias entre la dieta juvenil y la adulta de los individuos a los que se hizo análisis de isótopos estables al molar 3 (Figura 4), ni diferencias significativas por sexo.

\section{Bato}

La muestra Bato se compone de nueve individuos costeros, de los sitios Cancha de Golf $\mathrm{N}^{\mathrm{o}} 1$, El Trébol SE y Arévalo-2 y de dos individuos del valle, uno del sitio Hospital 8-9 y otro de Paso Agrícola, cuya filiación Bato es sólo sugerida por el 


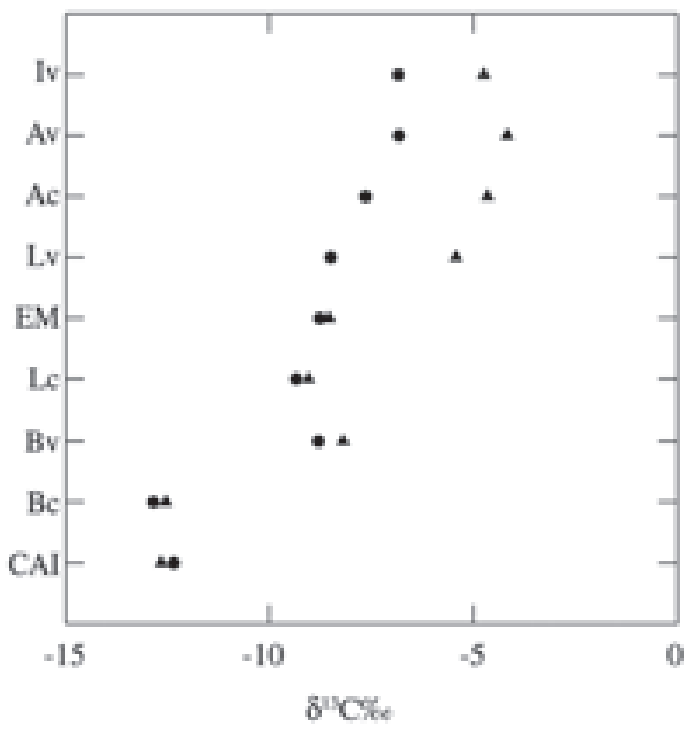

- Hucso A Molar

Figura 4. Gráfico con los valores $\delta^{13} \mathrm{C}$ promedio de los individuos con muestras de diente en cada contexto cultural estudiado. El resultado del esmalte de los terceros molares y de la apatita de los huesos muestra que las poblaciones con ausencia o bajo consumo de maíz no muestran diferencias entre la dieta adulta y la juvenil [Comunidades Alfareras Iniciales (CAI), Bato costa $(\mathrm{Bc})$, Bato valle $(\mathrm{Bv})$, Llolleo costa $(\mathrm{Lc})$ y Llolleo del sitio El Mercurio (EM)], a diferencia de las poblaciones donde la ingesta de maíz es mayor, quienes presentan un enriquecimiento de $\mathrm{C} 4$ en la etapa juvenil [Llolleo valle (Lv), Aconcagua costa (Ac), Aconcagua valle (Av) e Inca valle (Iv)]. Graph with the mean $\delta^{13} \mathrm{C}$ values from individuals with analyzed teeth according to cultural context. The results of third molar enamel and human bone apatite show that non maize or low maize consumers have the same diet as child and as adult [Comunidades Alfareras Iniciales (Initial Potter Communities) (CAI), Bato coast (Bc), Bato valley (Bv), Llolleo coast (Lc) and Llolleo from site El Mercurio (EM)]. Maize consumers have a diet enriched in C4 during childhood [Llolleo valley (Lv), Aconcagua coast, Aconcagua valley (Av) and Inca valley (Iv)].

patrón funerario ${ }^{8}$. A excepción de Arévalo-2 que tiene una serie de fechados RC14 y TL entre 300 a.C. y 150 d.C., los otros se sitúan en épocas posteriores al 500 d.C.

El individuo de Paso Agrícola presenta una dieta C3. El de Hospital 8-9 tiene un enriquecimiento evidente del carbono $\left(\delta^{13} \mathrm{Cap}-8,8 \%\right.$ ), que sólo se explica por la ingesta de algún vegetal $\mathrm{C} 4 \mathrm{o}$ de algas marinas. Dado que en la zona no tenemos evidencias de plantas silvestres $\mathrm{C} 4$ y que en otros registros arqueobotánicos de Chile central posteriores al 500 d.C. aparece el maíz, parece razona- ble pensar en la incorporación de este cultivo a esta dieta, aunque no existan a la fecha datos arqueobotánicos de esta especie en los contextos Bato. Si fuese el maíz el vegetal responsable del valor $\delta^{13} \mathrm{C}$, aplicando un fraccionamiento de $12 \%$ la proporción de maíz en la dieta total es de ca. $28 \%$. Descartamos el consumo de algas, ya que tendría que haber sido de grandes proporciones para que diera cuenta de la señal $\delta^{13} \mathrm{C}$ obtenida y haber afectado el nitrógeno. Además los valores $\delta^{18} \mathrm{O}$ del hueso y del diente son coherentes con las señales del valle central, por lo que creemos que este individuo permaneció en el interior a lo largo de su vida.

Los individuos encontrados en la costa presentan gran variabilidad. Algunos con bajo $\mathrm{C}$ y bajo $\mathrm{N}$ y otros más enriquecidos en ambos (Figura 3). Los primeros tienen valores semejantes a los individuos arcaicos de la zona (del litoral y del interior) y, si bien fueron enterrados en la costa, los recursos del mar no fueron parte de su dieta. Los otros, en cambio, más enriquecidos en $\mathrm{N}$ incorporan estos productos a su alimentación. Los recursos marinos serían de niveles bajos en la cadena trófica (p. ej. algas, moluscos y peces herbívoros). Si bien es difícil de evaluar, no parece haber incorporación de plantas $\mathrm{C} 4$ en la dieta o, si la hubo, la ingerencia fue mínima y sólo en algunos individuos.

No se aprecian diferencias entre la dieta juvenil y la adulta, ni en la costa ni en el interior, de los individuos a los que se hizo análisis de isótopos estables al molar 3 (Figura 4), ni diferencias significativas por sexo.

Estos resultados tienen implicancias interesantes desde el punto de vista del complejo cultural Bato y de sus sistemas de subsistencia-asentamiento. Lo primero que cabe señalar es la diversidad encontrada. Esta visión es algo que escapaba totalmente al análisis arqueológico y arqueofaunístico de sitios como Cancha de Golf $\mathrm{N}^{\circ} 1$ y El Trébol SE, los que están representados por cuatro individuos cada uno y en los que aparecen estos dos "tipos" de dieta. El registro arqueológico es tomado como el producto promedio de los recursos utilizados (tanto para la alimentación como para otros fines) y desechados, y lo que ahora estamos viendo es que los individuos Bato "costeros" presentan distintas combinaciones alimentarias, incluso los que habitaron un mismo lugar, y diferentes grados de dependencia de los productos del mar. Esta variedad no parece corresponder a diferencias cronológicas. Lo segundo es que los datos isotópicos 
son coherentes con el modelo de cazadores-recolectores con algo de horticultura que se maneja para estos grupos en la literatura, así como con estrategias de asentamiento con movilidad a lo largo de la costa y hacia el interior. Si bien todas las muestras costeras tienen valores $\delta^{18} \mathrm{O}$ altos, esto último se infiere del perfil alimentario terrestre de algunos de estos individuos enterrados en la costa. Por último, es interesante como cambia la comprensión del registro arqueofaunístico. En el caso del sitio Arévalo-2, para el cual existe un buen registro de fauna (Planella y Falabella 1987), la presencia de otáridos hacía pensar que los mamíferos marinos tuvieron importancia en la dieta, no obstante los resultados isotópicos muestran que fue menor.

\section{Llolleo}

Para los grupos Llolleo de interior contamos con 21 muestras, la mitad de ellas del sitio arqueológico El Mercurio y las restantes provenientes de cuatro sitios de la cuenca de Santiago y tres de la cuenca de Rancagua. Los contextos Llolleo tienen gran amplitud cronológica, entre 350 y 1.000 d.C.

Los resultados de la apatita forman dos conjuntos; en uno se agrupan los individuos del sitio El Mercurio con valores $\delta^{13} \mathrm{C}$ más negativos y en otro todos los restantes con valores más positivos (Tablas 2 y 4). Esta diferencia en el enriquecimiento de $\delta^{13} \mathrm{C}$ señala menor consumo de maíz en El Mercurio ( $27 \%$ de la dieta total) que en los otros sitios (35\% de la dieta total). Este resultado es inesperado. En este sitio se han rescatado restos de mazorcas y cariopses carbonizados de maíz en dos vasijas y dos urnas y algunas de ellas contenían residuos de color amarillento cuyos fitolitos parecen también corresponder a un "preparado" en base a Zea mays (Planella y McRostie 2005a). Además existe un abundante complejo artefactual de molienda morfológicamente adecuado a la producción de harinas (Vásquez 2000). Desde la evidencia cronológica y artefactual no existen distinciones entre El Mercurio y el resto de sitios Llolleo que hicieran predecir una diferencia de esta naturaleza en la alimentación, como tampoco que los individuos Llolleo de El Mercurio pudieran coincidir, en este aspecto de la dieta, con individuos Bato del valle. En este sitio los huesos estaban muy deteriorados y en la mayoría no se logró obtener colágeno. Los resultados de la apatita del hueso y del molar son muy coherentes, así como los resulta- dos de los individuos entre sí, lo que nos hace estimar que los resultados de la apatita son confiables, a excepción del individuo $\mathrm{N}^{\mathrm{o}} 13$ que entregó valores incoherentes entre el colágeno y la apatita, éste último significativamente distinto al promedio del sitio y al del esmalte dental, por lo que podría estar contaminado.

La población de los restantes sitios Llolleo de valle (Country Club, Villa Virginia, Lonquén, Alto Jahuel, Condominio Los Llanos, Las Pataguas, Las Coloradas, La Granja) tienen perfiles isotópicos bastante regulares y similares entre la cuenca del Maipo y la del Cachapoal. De éstos sólo La Granja ha sido extensivamente excavado (Ciprés Consultores 2002; Planella et al. 1997). Si bien el registro es especial por tratarse de una gran área con una sucesión de ocupaciones y sectores de función ritual, los vegetales y fauna recuperados son especies conocidas, manejadas y utilizadas por estas poblaciones. En el caso de la fauna, la especie más abundante es el guanaco y los restos presentan características que implican el transporte al sitio, desde el lugar de caza, de las partes anatómicas de mayor rendimiento. Esta estrategia es común a otros sitios Llolleo (Becker 1995-1996). En relación a los vegetales, junto con una variada gama de restos de plantas silvestres, se encontró un conjunto significativo de restos carbonizados de especies cultivadas (Chenopodium quinoa, Zea mays, Lagenaria sp. Phaseolus sp.) (Planella y Tagle 1998). La utilización de éstas para la vida cotidiana o su uso preferencial en el marco de las actividades ceremoniales era algo que no había podido ser dilucidado en investigaciones previas. Con los resultados isotópicos podemos evaluar al menos el consumo de maíz, el que parece haber sido suficientemente regular como para representar cerca del $35 \%$ del total de la dieta de los individuos estudiados.

En relación a variaciones entre la dieta adulta y juvenil, El Mercurio se comporta sin diferencias, al igual que los grupos CAI y Bato. En cambio en el resto de los sitios Llolleo los valores en estas distintas etapas de la vida son diferentes, con senales que indican mayor consumo de plantas $\mathrm{C} 4$ en la niñez (Figura 4). No se advierten diferencias significativas por sexo.

En la costa se analizaron ocho individuos de los sitios arqueológicos Los Puquios, LEP-C, Tejas Verdes 4 y Tejas Verdes 5, que son significativamente distintos en alimentación respecto a los 
Llolleo de interior, a excepción de un individuo masculino del sitio TV5, y presentan cierta dispersión en sus valores isotópicos (Tabla 2, Figura 3), lo que significa variabilidad en la dieta. El consumo de maíz que podemos inferir para estos costeros es de una proporción similar a la de El Mercurio, por lo tanto menor que en la mayoría de los sitios Llolleo de los valles. Estos valores reflejan una dieta mixta con productos marinos de baja escala trófica (mariscos, algas, algo de peces), probablemente un poco de fauna terrestre (guanaco), vegetales $\mathrm{C} 3$ y maíz. Existe variación tanto del nitrógeno en función del tipo de recurso marino como variación de $\delta^{13} \mathrm{C}$ del colágeno (proteína) y la apatita (dieta total). En los sitios costeros se han encontrado restos arqueobotánicos y faunísticos como para dar cuenta de esta dieta, sin embargo las abundancias sugerían aportes proporcionalmente diferentes (Falabella y Planella 1979; Falabella y Planella 1991). En LEP-C se han encontrado frutos y semillas de plantas silvestres comestibles C3, como peumo (Cryptocaria alba) y coco de palma chilena (Jubaea chilensis), una variada gama de moluscos, peces principalmente de orilla y de pozas intermareales, guanacos, aves y fauna de laguna como el coipo y la rana (Falabella y Planella 1991). Se obtuvieron escasos restos de plantas cultivadas en el análisis de las tierras flotadas del contenido de las vasijas (Planella y McRostie 2005b). Sin embargo en el sitio TV4, al interior de una urna, se recuperó un rico contexto que incluía quínoa, maíz, Lagenaria sp., documentando una variedad de plantas cultivadas asociadas a una mujer, con fecha AMS de 890-1.020 d.C. calibrada (Planella 2005)

Esta dieta "costera" de los Llolleo es muy distinta a la de los individuos Bato del litoral, pese a ser relativamente contemporáneos y a ocupar ambientes semejantes. La principal diferencia está en un mayor consumo de plantas $\mathrm{C} 4$ entre los Llolleo que, como hemos visto, debe corresponder al maíz. En cambio parecen aprovechar los mismos tipos de recursos marinos que los individuos Bato.

En los individuos Llolleo de la costa la dieta juvenil y la adulta es similar (Figura 4), y no se registraron diferencias significativas por sexo.

La clara distancia entre los valores isotópicos de individuos de costa e interior está mostrando que ellos vivían regularmente sólo en uno de esos ambientes, lo que confirma los modelos preexistentes. Esta apreciación deriva tanto de la dieta como del $\delta^{18} \mathrm{O}$. Se detectó sólo un caso, de TV 5, con un valor $\delta^{15} \mathrm{~N} 7,7 \%$, muy bajo para una dieta marina y que corresponde a un tipo de alimentación en base a recursos terrestres.

\section{Aconcagua}

En el caso Aconcagua se analizó un total de 28 muestras: ocho individuos de tres sitios arqueológicos de la costa (Las Brisas 10-14, Tejas Verdes 5 y Sto. Domingo); nueve de cuatro sitios del curso medio del río Maipo (María Pinto, El Bajo de Melipilla, Chiñique 2, Pomaire) y 11 de cuatro sitios de la cuenca de Santiago (Las Mercedes, Valle Chicauma, El Almendral, Carrascal 3). El rango cronológico va desde ca. 1.000 a 1.450 d.C.

El resultado más destacable es el significativo enriquecimiento del $\delta^{13} \mathrm{C}$ en relación a la población Llolleo. En el caso costero, el aumento del $\delta^{13} \mathrm{C}$ sin que aumente el $\delta^{15} \mathrm{~N}$ sugiere que la diferencia radica en el maíz. En el caso del interior, todos los individuos Aconcagua tienen el $\delta^{13} \mathrm{Ccol}$ más alto que cualquier muestra Llolleo y la diferencia es mayor en el colágeno (ca. 2\%o), es decir, en las proteínas, que en la apatita (ca. 1\%o). Una posibilidad es que aumente el consumo de maíz y disminuya el de carne de forma tal que la proteína del maíz tenga mayor representatividad. Esta alternativa va contra la evidencia arqueológica que muestra un aumento en el registro de guanacos en los sitios Aconcagua y no se condice con las señales del $\delta^{15} \mathrm{~N}$ que está marcando un leve aumento de la proteína animal. Otra posibilidad es que, junto con el aumento del maíz, los guanacos que consume la población Aconcagua estén comiendo no sólo pastos $\mathrm{C} 3$ sino también rastrojos de maíz. Se trata de una interpretación que es coherente con los planteamientos de Becker (1993) sobre aguachamiento del animal y con la disminución del espaciamiento colágeno-apatita que muestran los datos de la población Aconcagua. La información isotópica de las muestras de guanaco analizadas por nosotros de sitios de este componente cultural, sin embargo, no marca una dieta de este tipo (Tabla 1). Dado que se trata sólo de dos casos, es una posibilidad que debe quedar abierta y ser evaluada a futuro. Otra alternativa al aumento del $\delta^{13} \mathrm{C}$ es que exista un aporte de recursos marinos en la dieta. Éstos deberían ser recursos de bajo nivel trófico, como podría ser el caso de algunas algas ${ }^{9}$, para que sea compatible con los resultados. Esta expli- 
cación es viable con la evidencia arqueológica (ver más abajo). Si bien las posibilidades arriba mencionadas pueden influir en los resultados creemos que son complementarios a un claro aumento en el consumo de maíz. En el caso que el enriquecimiento fuera sólo por el maíz, el valor promedio $\delta^{13} \mathrm{Ccol}-11,6 \%$ y $\delta^{13} \mathrm{Cap}-6,6 \%$ o del interior estaría representando $56 \%$ de la fracción proteica y $43 \%$ de la dieta total. Dicho aumento resulta coherente con la abundancia de registros de corontas y cariopses de Zea mays en los sitios domésticos Aconcagua, los que aparecen recurrentemente asociados a un complejo de especies cultivadas como la quínoa, porotos, zapallos y calabazas (Planella 2005; Quiroz 2004). También es coherente con la propuesta de una intensificación de la cocción de alimentos, debido al abundante hollín y la buena conductividad de las paredes de las ollas Aconcagua (Falabella 2000b).

Otro resultado de interés es que, en este grupo humano, sí se encontraron valores significativamente distintos de carbono entre masculinos (dieta más enriquecida en $\delta^{13} \mathrm{C}$ ) y femeninos (dieta más empobrecida en $\delta^{13} \mathrm{C}$ ), (pooled variance $\mathrm{t}=-2,59$; $\mathrm{df}=12 ; \mathrm{prob}=0,02)$. Esta diferencia no se da en todos los individuos, sino sólo en el caso de los individuos del interior. Los dientes, al igual que en el caso de los Llolleo de valle, muestran mayor consumo de plantas C4 durante la niñez, diferencia del orden de 2,5\%o (Figura 4).

En la costa una parte de las muestras tiene dieta mixta muy similar en lo marino a las muestras Bato y Llolleo pero de $\delta^{13} \mathrm{C}$ más positivo (Tabla 2, Figura 3). Aparece aislado un individuo Aconcagua del sitio Las Brisas 10-14 (ind. $\mathrm{N}^{\circ} 24$ ), al sur de la desembocadura del río Maipo, con valores de $\delta^{13} \mathrm{C}$ $17,3 \%$ y $\delta^{15} \mathrm{~N} 14,3 \%$. El bajo valor de carbono del colágeno indica probablemente menor cantidad de productos marinos y menos maíz, mientras que el alto valor de $\delta^{15} \mathrm{~N}$ sugiere una dependencia significativa de peces de agua dulce o que habitan entre los ambientes marinos y lacustres. Esta probabilidad es coherente con la cercanía a lagunas donde el Micropogonia furnieri (roncador) pudo habitar y con la presencia de esta especie en el registro de los sitios litorales al sur del río Maipo.

Los otros cuatro individuos están empobrecidos en $\delta^{13} \mathrm{C}$ y $\delta^{15} \mathrm{~N}$ (Tabla 2, Figura 3 ). Estos valores denotan una reducción general de los productos marinos y/o aumento de la ingesta de legumbres como el poroto, lo que nos lleva a pensar que se- rían individuos que no habitan permanentemente el litoral sino que transitan entre los valles del interior y la costa o que habrían llegado al litoral pocos años antes de su muerte, o bien, si habían llegado hace mucho, mantuvieron sus hábitos alimentarios originarios del interior.

Dos de los individuos de la costa presentan las mismas diferencias entre la dieta juvenil y la adulta que los individuos del valle (Figura 4). El tercero muestra un resultado anómalo, una dieta juvenil muy empobrecida en $\mathrm{C} 4$ respecto a la adulta (Tabla 2).

También es interesante que la mayoría de los individuos Aconcagua del interior, en forma especial los de la zona cercana a Melipilla, tienen valores de nitrógeno más altos que las otras poblaciones alfareras, que puede reflejar algo de aporte marino en su dieta. La movilidad costa-interior se podría avalar también para tres individuos de María Pinto (valle del estero Puangue al norte de Melipilla) que tienen valores $\delta^{18} \mathrm{O}$ muy altos, uno de ellos más marcado en la niñez (ind. $\mathrm{N}^{\circ} 11$ ).

Los resultados de $\delta^{18} \mathrm{O}$ refuerzan el vínculo de la costa preferencialmente con los valles del curso medio del río Maipo durante el período Intermedio Tardío. El ordenamiento, de menor a mayor de estos valores, muestra un empobrecimiento desde la costa al interior. Los individuos Aconcagua de María Pinto (estero Puangue) y Chiñigue 2 tienen valores intermedios que sugieren acercamiento marcado al litoral. Pomaire, Villa Galilea y El Bajo de Melipilla, en cambio, marcan el hábitat intermedio. Por otra parte, algunos individuos del sitio costero Las Brisas 10-14, muestran perfiles más empobrecidos que los que corresponden en general a la población litoral. Esta configuración de los valores de isótopos estables obtenidos para la población Aconcagua está apoyando la tesis de movilidad y estrechos vínculos entre los asentamientos de la costa y los del curso medio del río Maipo que han sido planteados a la luz de fuentes históricas y de análisis cerámicos (Falabella et al. 2002, 2003), así como con el registro de restos, aunque muy ocasionales, de especies marinas en las basuras de los sitios del valle central que podrían estar validando un movimiento de personas y/o recursos (Pavlovic 2000).

\section{Inca}

La asignación al período de contacto inca se basó en el contexto de ofrendas cerámicas de los 
individuos que presentaran claros patrones de forma y decoración asignables a este período. Las muestras provienen sólo de sitios del interior (Villa Galilea en la zona de Melipilla; Las Tinajas de Quilicura, Nos, Línea 5 Metro, Carrascal 1 en la cuenca de Santiago) (Tabla 2). La ocupación inca del litoral fue circunstancial en Chile central y no se dispone de restos humanos adultos para analizar de la costa. El rango temporal debiera situarse entre 1.450 y 1.550 d.C. (no más de unos 100 años) dentro de cuyo lapso se insertan las fechas del sitio Línea 5 del Metro (Reyes 2003) (Tabla 3). Esta población puede corresponder a individuos "Aconcagua aculturados" o a individuos foráneos llegados a la zona con el Inca. En la arqueología local se utiliza el patrón estilístico de las vasijas de ofrenda como indicador de la identidad y/o proximidad social con el Tawantinsuyu (Cantarutti y Mera 2002).

Los valores promedio de isótopos estables que entrega la población de contacto inca (Tabla 4) no coinciden con las expectativas. Se esperaba un incremento de la señal C4 en función de las referencias documentales a la existencia de canales de regadío y abundancia de tierras con cultivo de maíz. Por el contrario, la mayoría de los individuos analizados tiene valores similares a los grupos Llolleo del valle y menores que los Aconcagua (Figura 3). Sólo unos pocos $(\mathrm{n}=3)$ presentan patrones de consumo $\mathrm{C} 4$ tan altos como las poblaciones Aconcagua: el individuo $\mathrm{N}^{\circ} 3$ del sitio Las Tinajas de Quilicura que coincide con el que presenta el contexto de ofrendas más abundante de los muestreados; la tumba $\mathrm{N}^{\circ} 14$ de Nos, asociado a 4 vasijas inca local y el individuo $\mathrm{N}^{\circ} 1$ del sitio Línea 5 Metro con ofrendas de vasijas fase inca.

No se aprecian diferencias significativas por sexo. De los dos dientes analizados (ambos femeninos), uno tiene un espaciamiento de $3 \%$ respecto de la apatita y el otro es más cercano al valor del hueso (1\%o), es decir, al menos uno tuvo una dieta diferente en la juventud.

Si una parte importante del enriquecimiento de carbono de la población Aconcagua es debida al consumo de maíz, la única explicación razonable para el caso Inca es una disminución de la proporción de este cultivo en la dieta total. Si tenemos como referente la importancia del maíz en el Tawantinsuyu (Hastorf y Johannessen 1993) debemos explorar en qué forma el significado y función del maíz entre la población inca puede haber afectado las formas de producción, distribución y uso de este cultivo en Chile central. Creemos que los documentos históricos transmiten un hecho real, la existencia de tierras destinadas al cultivo de maíz así como acequias y canales de regadío ya que esta planta requiere de mucha agua. Sin embargo no tenemos por qué pensar que toda esa producción estuvo destinada a la alimentación. Más bien, los datos de otras regiones del Tawantinsuyu se refieren a las cosechas de maíz en especial relacionadas a las festividades y a las necesidades de reciprocidad dentro del sistema de poder incaico (Hastorf y Johannessen 1993). Si hubo ampliación de los cultivos para estos fines, por cierto no incidirá en el consumo de las familias locales. Es más, pensamos que la demanda del estado pudo incidir en que la población local tuviera que buscar sustitutos alimentarios, lo que llevó a una baja en la proporcionalidad del maíz versus otras fuentes de carbohidratos. Este mismo resultado isotópico se obtendría por un incremento del consumo de ciertos alimentos típicamente andinos, como son la papa y la quínoa. En especial es interesante pensar en la posibilidad de que el "chuño" pudiera haber sido transportado a grandes distancias por su capacidad alimentaria y de conservación.

$\mathrm{Si}$ el incremento de carbono de la población Aconcagua depende en algún grado del consumo de algas, lo que estaría señalando el caso Inca es un descenso significativo de aporte de vegetales marinos, que implica un cambio respecto de los patrones de complementación de recursos entre la costa y el interior.

Un solo individuo Inca del sitio Villa Galilea de la zona de Melipilla (curso medio del río Maipo) -equidistante de la cuenca de Santiago y de la costa-muestra enriquecimiento de nitrógeno (Figura 3). Sería un caso análogo a los Aconcagua de esta zona. Un individuo masculino de Nos (ind. $\mathrm{N}^{\mathrm{o}} 1 \mathrm{c}$ ) podría ser foráneo porque el valor de la apatita está fuera del rango de su grupo y el $\delta^{18} \mathrm{O}$ es extremadamente bajo (no tiene valor de colágeno); la ofrenda que lo acompaña es un plato inka-diaguita.

\section{Conclusiones}

A través de este estudio hemos mostrado que los análisis de isótopos estables ofrecen muy buenas potencialidades para la reconstrucción dietética y de los sistemas de movilidad en el pasado. Hemos podido evaluar la mayor o menor depen- 
dencia de los productos marinos, el nivel trófico de los mismos, el consumo relativo de carne y la proporcionalidad entre plantas $\mathrm{C} 3$ y $\mathrm{C} 4$, aspectos sobre los cuales podemos esbozar algunas conclusiones.

En primer lugar, en el caso concreto de las sociedades alfareras prehispanas de Chile central, los valores que reflejan dietas distintas formaron agrupamientos diferenciados según contexto cultural y, en algunos casos, con escasa variación en torno a la media. A lo largo de la secuencia de desarrollo de los períodos alfareros, los grupos humanos, si bien ocuparon los mismos espacios y tuvieron acceso a recursos similares, buscaron combinaciones diferentes según sus particulares opciones culturales, tecnológicas y de organización social.

En segundo lugar, se obtuvo información importante del contraste entre dietas marinas y terrestres. Contrario a lo esperado, los resultados no muestran una adaptación al litoral de los habitantes de la costa y revelan que las poblaciones que ocuparon esos espacios no siempre se alimentaron de recursos del mar. De hecho, ninguno de los grupos estudiados optó por una dieta francamente marina, ya que este tipo de recursos fue sólo una parte menor de lo que se consumía y alimentos tan nutritivos como los mamíferos marinos, por ejemplo, por sus contenidos en lípidos, no fueron foco preferente en las dietas de Chile central. Los valores isotópicos de estas poblaciones, especialmente del $\delta^{15} \mathrm{~N}$, son notoriamente más bajos que los de otras poblaciones costeras del litoral del Pacífico sur cuyos recursos tienen valores semejantes a los obtenidos en la zona central (Tieszen y Chapman 1992; Tieszen et al. 1992; Tomczak 2003). La reconstrucción dietética que se había realizado en base a los artefactos y restos arqueofaunísticos, si bien establecía que ningún grupo del período alfarero de Chile central desarrolló una especialización en las actividades marinas, sugería para todos ellos un insumo mucho mayor de moluscos, peces, mamíferos y aves que lo que reflejan los isótopos.

La comparación entre dieta marina y terrestre también mostró diferencias en el sistema de asentamiento a lo largo del tiempo. Para los grupos Bato, donde encontramos una enorme variabilidad entre los individuos de los mismos sitios, los antecedentes arqueológicos nos llevaron a pensar que la movilidad a lo largo del litoral y la movilidad costainterior quizás sería una interpretación razonable. El caso Llolleo, por el contrario, nos mostró po- blaciones habitando territorios definidos a lo largo de sus vidas, con escaso movimiento entre ambientes. En el caso Aconcagua, la información isotópica aportó nuevos antecedentes para apoyar la propuesta de integración de los espacios costeros con los valles de la cordillera de la costa.

En tercer lugar, la información sobre el aporte de plantas C4 a la dieta es otro de los resultados sustantivos. Los datos isotópicos tuvieron buena resolución para aclarar el momento en que el maíz empieza a ser importante como fuente de sustento, cuando éste se intensifica y para estimar la mayor o menor regularidad en el uso de este cultivo para fines alimentarios dentro de cada contexto cultural.

Las Comunidades Alfareras Iniciales claramente no muestran aportes de maíz a la dieta, lo que es consistente con la ausencia de restos arqueológicos de este cultivo en estos contextos y en el período inicial de la etapa alfarera en Chile central (300 a.C.-200 d.C.). En la población Bato de la costa es difícil distinguir si lo hubo o no porque las señales se confunden con el enriquecimiento por consumo de recursos marinos. El individuo Bato del sitio Hospital 8-9, fechado en 575-766 cal. d.C., tiene una dieta parcialmente sustentada en maíz, lo que sugiere que el lapso entre 200-500 d.C. puede ser el momento en que este cultivo ingresa, se va adaptando y es consumido en algunas comunidades o por algunos individuos de Chile central. Correspondería a una etapa inicial donde se espera alta variabilidad entre individuos y comunidades. La población Llolleo es la que aparentemente adopta definitivamente este cultivo como fuente estable de sustento. Los valores de casi todos los individuos de muchos sitios del valle son muy similares, lo que nos lleva a pensar que en la población Llolleo del interior hubo una dependencia del maíz para alimentarse. Sin embargo, como se mencionara antes, dentro del grupo cultural Llolleo, los individuos asentados en la costa y los del sitio El Mercurio tienen menor consumo que los de los otros sitios muestreados. Los costeros, dentro de su variabilidad, marcan más maíz que los Bato y menos que los Aconcagua del litoral.

Los valores más altos de $\delta^{13} \mathrm{C}$ de toda la secuencia prehispana se encuentra en la población Aconcagua. Si bien parte del enriquecimiento puede deberse al aporte de recursos marinos, existe una diferencia con las otras poblaciones que hace pensar que se trata de la estrategia alimentaria con mayor intensidad de consumo de maíz. 
El caso inca plantea un problema interesante de interpretación. Si el maíz fuera la única fuente de enriquecimiento de carbono, los datos indicarían una merma en su consumo durante el período Tardío con interesantes implicancias político-sociales. Nos queda la inquietud, sin embargo, de no poder controlar la incidencia de las algas marinas en la dieta, algo que desde el punto de vista de la nutrición es altamente provechoso y que en la tradición alimentaria de los grupos indígenas está presente. Si seguimos la lógica de los patrones de integración entre costa e interior antes discutidos, el factor "algas" podría ser significativo en el enriquecimiento isotópico de la población Aconcagua del valle, en cuyo caso la diferencia entre la dieta de la población Aconcagua y la del período de contacto Inca adquiere un cariz diferente. En vez de corresponder a diferencias en el consumo de maíz, podría deberse al cese de consumo de algas y desarticulación de las redes de complementación económica y/o social. Se necesita mayor información para afinar estas interpretaciones.

Un cuarto aspecto es el gran espaciamiento entre el colágeno y la apatita que sugiere dietas fuertemente basadas en los vegetales y que deja abiertas algunas preguntas importantes que deberemos investigar más adelante. Los resultados sugieren que las plantas silvestres y/o cultivadas fueron siempre las fuentes primarias de alimentación. Por otra parte, a medida que aumenta la ingesta de maíz, si la fuente de proteínas animal se mantiene estable (los mismos guanacos alimentados con pastos C3), el espaciamiento debería aumentar. Nuestros resultados muestran lo contrario. En cambio, si los guanacos comieran los rastrojos de maíz acercándose a los hogares de horticultores, situación probable de acuerdo a los planteamientos de Becker (1993) para el caso Aconcagua, el espaciamiento disminuiría y podría explicar los resultados.

Un quinto aporte novedoso es la diferencia en la dieta de hombres y mujeres sólo en la población Aconcagua. Una parte de la población masculina tendría mayor consumo de maíz o, siguiendo el argumento sobre las algas que hicimos antes, mayor ingesta de vegetales marinos que cualquier mujer. Sea cual fuere el o los recursos que inciden en esta diferencia, lo que adquiere relevancia social es que se produce un distingo por género (estadísticamente significativo) que viene a mostrar una faceta antes desconocida en la organización social de esta población y que se suma a tantos otros cambios que marcan el paso desde el período Alfarero Temprano al Intermedio Tardío en el centro de Chile.

Un último aspecto a considerar en estas conclusiones se refiere a la información aportada por la comparación entre hueso y diente de los mismos individuos. En los casos en que hay altos valores $\delta^{13} \mathrm{C}$ (Llolleo de valle, Aconcagua de valle, Aconcagua de costa e Inca) los dientes muestran claramente un enriquecimiento isotópico en relación al hueso. Este puede deberse a mayor cantidad relativa de maíz o algas en la dieta juvenil que en la etapa de la adultez. En el primer caso, existe la posibilidad que los niños estén siendo alimentados con algún tipo de papilla a base de maíz como opción dietética; en el segundo caso, puede deberse al traslado desde el lugar de asentamiento juvenil. Dados los antecedentes en relación a los indicadores de movilidad de las poblaciones prehispanas de Chile central, creemos que estos tres grupos sociales no manejan las mismas estrategias de asentamiento e integración regional como para buscar un factor común a todos ellos. Nos inclinamos a pensar que se trata de una causal relacionada con las necesidades y opciones de nutrición infantil en comunidades donde la horticultura de maíz se ha afianzado y este cultivo se ha integrado en forma sólida y estable a la dieta general, sin descartar que en el caso de los Aconcagua costeros se deba a la movilidad. Así cobra sentido que esta particularidad esté presente en distintos grupos sociales, pero sólo en aquellas comunidades que han mostrado alta incidencia de maíz en su alimentación.

\section{Reflexión Final}

La dieta es una de las tantas soluciones que los grupos humanos deben incorporar para habitar y desarrollarse en sus territorios. De acuerdo a sus particulares opciones culturales, desarrollo tecnológico y necesidades sociales, cada grupo humano define una estrategia de obtención, preparación y uso de recursos alimenticios, los que configuran su particular sistema de subsistencia. Estas estrategias constituyen un aspecto sustantivo de los modos de ser y hacer de cada grupo humano. Al igual que las tradiciones líticas, alfareras, espaciales u otras, los patrones alimentarios son elecciones culturales que configuran estilos tecnológicos particulares. Qué comen, cuándo lo comen, quie- 
nes lo comen, dónde, cuándo y cómo lo obtienen son todas preferencias resultado de las disposiciones socialmente validadas y sancionadas en cada sociedad, tanto en períodos de estabilidad como de estrés y cambio.

El estudio realizado nos ha permitido conocer facetas distintas de estas opciones alimentarias en las poblaciones alfareras de Chile central. Más allá de poder determinar las proporciones en que distintos grupos de alimentos participaron de la dieta de cada conjunto cultural, la variabilidad intra e interindividual y los matices entre comunidades, han enriquecido nuestra visión de las sociedades estudiadas. La información isotópica ha empezado a llenar ciertos espacios vacíos en la búsqueda del conocimiento sobre la relación de estos grupos prehispanos con sus recursos y la forma en que lograron encontrar soluciones fisiológicas y sociales viables para mantener la salud y estabilidad de la población. Esperamos que esta línea analítica siga ofreciendo nuevos datos para avanzar en la comprensión de los sistemas de subsistencia, mo- vilidad y relaciones sociales de las poblaciones de Chile central.

Agradecimientos: Este trabajo fue financiado por los proyectos FONDECYT No 1040553 y $\mathrm{N}^{\mathrm{o}} 7040154$. La etapa de definición y selección de las muestras contó con la buena disposición de las instituciones que guardan las colecciones bioantropológicas estudiadas (Universidad de Chile, $\mathrm{Mu}$ seo Nacional de Historia Natural, Museo Regional de Rancagua, Museo de Historia Natural de San Antonio, Museo Chileno de Arte Precolombino, Consejo de Monumentos Nacionales) y la generosa colaboración de varios colegas, en especial de Silvia Quevedo, José Luis Brito, Pilar Rivas, Carlos Ocampo, Catherine Westfall, Mario Henríquez, Iván Cáceres, Rodrigo Sánchez, Luis Cornejo, Nuriluz Hermosilla, Mario Vásquez y Claudia Prado, quienes proporcionaron materiales e información inédita para esta investigación. El manuscrito se benefició de los comentarios de tres evaluadores y de los editores de la revista Chungara.

\section{Referencias Citadas}

\section{Ambrose, S.H.}

1993 Isotopic analysis of paleodiets: Methodological and interpretative considerations. En Investigations of Ancient Human Tissue. Chemical Analysis in Anthropology, editado por M.K. Sandford, pp. 59-130. Breach Science Publishers, Pennsylvania.

Ambrose, S.H. y L. Norr

1993 Experimental evidence for the relationship of the carbon isotope ratios of whole diet and dietary protein to those of bone collagen and carbonate. Prehistoric Human Bone: Archaeology at the Molecular Level, editado por J.B. Lambert y G. Grupe, pp. 1-38. Springer-Verlag, Berlin.

Ambrose, S.H., J. Buikstra y H.W. Krueger

2003 Status and gender differences in diet at Mound 72, Cahokia, revealed by isotopic analysis of bone. Journal of Anthropological Archaeology 22:217-226.

Becker, C.

1993 Algo más que 5.000 Fragmentos de Huesos. Memoria para optar al título profesional de arqueólogo, Universidad de Chile, Santiago.

1995-1996 Los huesos de un patio. Informe de fauna. Proyecto Fondecyt N ${ }^{\circ}$ 194-0457. Manuscrito en posesión de biblioteca Fondecyt.

Belmar, C. y L. Quiroz

1999a Informe flotación: sitios Hospital y Radio Estación Naval. Proyecto Fondecyt N ${ }^{\circ} 1970910$. Manuscrito en posesión de biblioteca Fondecyt.

1999b Informe arqueobotánico. Proyecto Fondecyt No 1980713. Manuscrito en posesión de biblioteca Fondecyt.
2000 Informe preliminar y arqueobotánico del sitio Peñaflor (E-301-2) y Puangue. Informe Proyecto Fondecyt $N^{\circ} 1980713$. Manuscrito en posesión de biblioteca Fondecyt.

2003 Informe de análisis carpológico. Proyecto de extensión Línea 5 del Metro, Estación Quinta Normal. Manuscrito en posesión de biblioteca Consejo de Monumentos Nacionales.

Bocherens, $\mathrm{H}$.

2000 Preservations of isotopic signals $(13 \mathrm{C}, 15 \mathrm{~N})$ in pleistocene mammals. En Biogeochemical Approaches to Paleodietary Analysis, editado por S.H. Ambrose y M.A. Katzenberg, pp. 65-88. Plenum: Advances in Archaeological and Museum Science 5, New York.

Cantarutti G. y R. Mera

2002 Alfarería del cementerio Estación Matucana: ensayo de clasificación y relaciones con la cerámica del período Inca de Chile central y áreas vecinas. Werken 3:147-170.

Ciprés Consultores

2002 Informe sitio arqueológico La Granja. Manuscrito en posesión de biblioteca Consejo de Monumentos Nacionales.

2003 Proyecto Las Brisas de Santo Domingo sur. Manuscrito en posesión de biblioteca Consejo de Monumentos Nacionales.

Durán, E. y M.T. Planella

1989 Consolidación agroalfarera: zona central (900 a 1470

d.C.). En Culturas de Chile. Prehistoria, editado por J. Hidalgo, V. Schiappacasse, H. Niemeyer, C. Aldunate e I. Solimano, pp. 313-328. Editorial Andrés Bello, Santiago. 
Durán, E., A. Rodríguez y C. González

1993 Sistemas adaptativos de poblaciones prehispánicas en el cordón de Chacabuco. Actas del XII Congreso Nacional de Arqueología Chilena. Boletín Museo Regional de La Araucanía $\mathrm{N}^{\circ}$ 4, Tomo II:235-248.

Falabella, F.

2000a El sitio arqueológico de El Mercurio en el contexto de la problemática cultural del período alfarero temprano en Chile central. Actas Segundo Taller de Arqueología de Chile Central (1993) Http://Members.Tripod.Cl/Lcbmchap/ Ferfall.Htm.

2000b El estudio de la cerámica Aconcagua en Chile central: una evaluación metodológica. Contribución Arqueológica, Museo Regional de Atacama $\mathrm{N}^{\circ}$ 5, Tomo I:427-58.

Falabella, F., E. Aspillaga, R. Morales, M.I. Dinator y F. Llona 1995-1996 Nuevos antecedentes sobre los sistemas culturales en Chile central sobre la base de análisis de composición de elementos. Revista Chilena de Antropología 13:2960.

Falabella, F., L. Cornejo y L. Sanhueza

2003 Variaciones locales y regionales en la cultura Aconcagua del valle del río Maipo. Actas IV Congreso Chileno de Antropología Tomo II, pp. 1411-1419. Colegio de Antropólogos, Santiago.

Falabella, F. y M.T. Planella

1979 Curso Inferior del Río Maipo: Evidencias Agroalfareras. Tesis de grado para optar al título de arqueólogo, Departamento de Antropología, Universidad de Chile, Santiago.

1988-1989 Alfarería temprana en Chile central: un modelo de interpretación. Paleoetnologica 5:41-64.

1991 Comparación de ocupaciones precerámicas y agroalfareras en el litoral de Chile central. En Actas XI Congreso Nacional de Arqueología Chilena Tomo 3, pp. 95-112. Museo Nacional de Historia Natural y Sociedad Chilena de Arqueología, Santiago.

Falabella, F., L. Sanhueza y E. Fonseca

2002 Una propuesta sobre la naturaleza de las materias primas de la cerámica Aconcagua Salmón. Chungara Revista de Antropología Chilena 34:167-189.

Falabella, F. y R. Stehberg

1989 Los inicios del desarrollo agrícola y alfarero: zona central (300 a.C. a 900 d.C.). En Culturas de Chile. Prehistoria, editado por J. Hidalgo, V. Schiappacasse, H. Niemeyer, C. Aldunate e I. Solimano, pp. 295-311. Editorial Andrés Bello, Santiago.

Fricke, H.C., J.R. O'Neil y N. Lynnerup

1995 Oxygen isotope composition of human tooth enamel from Medieval Geenland: Linking climate and society. Geology 23:869-872.

Harrison, R.G. y M.A. Katzenberg

2003 Paleodiet studies using stable carbon isotopes from bone apatite and collagen: examples from Southern Ontario and San Nicolas Island, California. Journal of Anthropological Archaeology 22:227-244.

Hastorf, C.A. y S. Johannessen

1993 Pre-Hispanic political change and the role of maize in the Central Andes of Peru. American Anthropologist 95:115-138.

Hermosilla, N., L. Lavanderos, B. Saavedra, L. Vargas y M. Carrasco
2003 Uso del espacio en los períodos Alfarero Temprano y Tardío: análisis comparativo. Actas IV Congreso Chileno de Antropología Tomo II, pp. 1419-1426. Colegio de Antropólogos, Santiago.

Katzenberg, M.A.

1992 Advances in stable isotope analysis of prehistoric bones. En Skeletal Biology of Past Peoples: Research Methods, editado por S.R. Saunders y M.A. Katzenberg, pp. 105-119. Wiley-Liss, New York.

2000 Stable isotope analysis: A tool for studying past diet, demography, and life history. En Biological Anthropology of the Human Skeleton, editado por M.A. Katzenberg y S.R. Saunders, pp. 305-327. Wiley-Liss, New York.

Keegan, W.F.

1989 Stable isotope analysis of prehistoric diet. En Reconstruction of Life from the Skeleton, editado por M.Y. Iscan y K.A.R. Kennedy, pp. 223-236. Alan R. Liss, New York.

Keegan, W.F. y M.J. DeNiro

1988 Stable carbon and nitrogen-isotope ratios of bone collagen used to study coral-reef and terrestrial components of prehistoric Bahamian diet. American Antiquity 53:320-336.

Little, E.A. y M.J. Schoeninger

1995 The Late Woodland diet on Nantucket Island and the problem of maize in coastal New England. American Antiquity 60:351-368.

Massone, M., E. Durán, R. Sánchez, F. Falabella, F. Constantinescu, N. Hermosilla y R. Stehberg

1998 Taller cultura Aconcagua: evaluación y perspectivas. Boletín de la Sociedad Chilena de Arqueología 25:24-30.

Newsome, S.D., D.L. Phillips, B.J. Culleton, T.P. Guilderson y P.L. Koch

2004 Dietary reconstruction of an early to Middle Holocene human population from central California coast: Insights from advanced stable isotope mixing models. Journal of Archaeological Science 31:1101-1115.

Norr, L.

1995 Interpreting dietary maize from bone stable isotopes in the American Tropics: The state of the art. En Archaeology in the Lowland American Tropics, editado por P. W. Stahl, pp. 198-233. Cambridge University Press, Cambridge.

Passey, B.H., T.F. Robinson, L.K. Ayliffe, T.E. Cerling, M. Sponheimer, M.D. Dearing, B.L. Roeder, y J.R. Ehleringer

2005 Carbon isotope fractionation between diet, breath $\mathrm{CO}_{2}$, and bioapatite in different mammals. Journal of Archaeological Science 32:1459-1470.

Pavlovic, D.

2000 Las casas de la gente del valle: el asentamiento habitacional de la cultura Aconcagua en la cuenca del MaipoMapocho. Actas 3er Congreso Chileno de Antropología Tomo I, pp. 410-422. Colegio de Antropólogos, Temuco.

Planella, M.T.

1988 La propiedad Territorial Indígena en la Cuenca de Rancagua a Fines del Siglo XVI y Comienzos del XVII. Tesis para optar al grado de Magíster en Historia, Universidad de Chile, Santiago.

1997 Restos alimenticios de origen vegetal en un contexto habitacional litoral de la cultura Aconcagua. Manuscrito en posesión de la autora.

2005 Cultígenos prehispanos en contextos Llolleo y Aconcagua en el área de desembocadura del río Maipo. Boletín de la Sociedad Chilena de Arqueología 38:9-23. 
Planella, M.T., L. Cornejo y B. Tagle

2005 Alero Las Morrenas 1: evidencias de cultígenos entre cazadores recolectores de finales del período Arcaico en Chile central. Chungara Revista de Antropología Chilena 37:59-74.

Planella, M.T. y F. Falabella

1987 Nuevas perspectivas en torno al período Alfarero Temprano en Chile central. Clava 3:43-110.

Planella, M.T., F. Falabella, B. Tagle y V. Manríquez

1997 Fundamentos prehispánicos de la población "promaucae" histórica. Proyecto Fondecyt No 194-0457. Manuscrito en posesión de biblioteca Fondecyt.

Planella, M.T. y V. McRostie

2005a Análisis de restos botánicos del sitio El Mercurio. Tierras contenidas en ceramios y urnas del contexto funerario. Proyecto Fondecyt $N^{\circ} 1040553$. Manuscrito en posesión de biblioteca Fondecyt.

2005b Residuos botánicos del sitio Laguna El Peral-C. Una nueva aproximación a la subsistencia en un asentamiento arqueológico del litoral de Chile central. Proyecto Fondecyt $\mathrm{N}^{\circ} 1040553$. Manuscrito en posesión de biblioteca Fondecyt.

Planella, M.T., V. McRostie, C. Belmar, L.Quiroz y G. Rojas 2006 Descripción y análisis de granos de almidón de muestras de referencia vegetales (domésticas y silvestres) y muestras de artefactos arqueológicos en Chile central. Proyecto de Cooperación Internacional, Fondecyt N 7050165. Manuscrito en posesión de biblioteca Fondecyt.

Planella, M.T. y R. Stehberg

1997 Intervención inka en un territorio de la cultura local Aconcagua de la zona centro-sur de Chile. Tawantinsuyu 3:58-78.

Planella, M.T. y B. Tagle

1998 El sitio agroalfarero temprano de La Granja: un aporte desde la perspectiva arqueobotánica. Publicación Ocasional del MNHN N 52 .

2004 Inicios de presencia de cultígenos en la zona central de Chile, períodos Arcaico y Agroalfarero Temprano. Chungara Revista de Antropología Chilena Volumen Especial Tomo I:387-399.

Quiroz, L.

2004 Informe análisis carpológico. Sitio Las Pataguas, Valdivia de Paine. Manuscrito en posesión de la autora.

Reimer, P.J., M.G.L. Baillie, E. Bard, A. Bayliss, J.W. Beck, C.J.H. Bertrand, P.G. Blackwell, C.E. Buck, G.S. Burr, K.B. Cutler, P.E. Damon, R.L. Edwards, R.G. Fairbanks, M. Friedrich, T.P. Guilderson, A.G. Hogg, K.A. Hughen, B. Kromer, G. McCormac, S. Manning, C.B. Ramsey, R.W. Reimer, S. Remmele, J.R. Southon, M. Stuiver, S. Talamo, F.W. Taylor, J. van der Plicht y C.E. Weyhenmeyer

2004 IntCal04 terrestrial radiocarbon age calibration, 0-26 cal kyr BP. Radiocarbon 46:1029-1058.

Reyes, V.

2003 Informe rescate cementerio período incaico, estación Quinta Normal. Informe 2a Etapa Proyecto Extensión Línea 5, Santa Ana-Matucana. Estaciones y Túneles Interestaciones. Manuscrito en posesión de biblioteca Consejo de Monumentos Nacionales.

Richards, M.P. y R.E.M. Hedges

1999 Stable isotope evidence for similarities in the types of marine foods used by Late Mesolithic humans at sites along the Atlantic coast of Europe. Journal of Archaeological Science 26:717-722.

Sánchez, R.

1995 Cultura material, arte, monumentos y cuerpos en el espacio. Prácticas mortuorias del complejo cultural Aconcagua. Hombre y Desierto 9:281-290.

Sanhueza, L.

2004 Estilos Tecnológicos e Identidades Sociales Durante el Período Alfarero Temprano en Chile Central: Una Mirada Desde la Alfarería. Tesis para optar al grado de Magíster en Arqueología, Universidad de Chile, Santiago.

Sanhueza, L. y F. Falabella

2003 Las comunidades alfareras iniciales de Chile central: continuidades y cambios desde el Arcaico Tardío a las sociedades hortícolas y alfareras. Actas IV Congreso Chileno de Antropología Tomo II, pp. 1405-1410. Colegio de Antropólogos, Santiago.

Sanhueza, L., M. Vásquez y F. Falabella

2003 Las sociedades alfareras tempranas de la cuenca de Santiago. Chungara Revista de Antropología Chilena 35:2350.

Schoeninger, M.J., M.J. DeNiro y H. Tauber

1983 Stable nitrogen isotope ratios of bone collagen reflect marine and terrestrial components of prehistoric human diet. Science 220:1381-1383.

Schwarcz, H.P.

2000 Some biochemical aspects of carbon isotopic paleodiet studies. En Biogeochemical Approaches to Paleodietary Analysis, editado por S.H. Ambrose y M.A. Katzenberg, pp.189-209. Plenum: Advances in Archaeological and Museum Science 5, New York.

Sealy, J.C. y N.J. van der Merwe

1986 Isotope assessment and the seasonal-mobility hypothesis in the southwestern Cape of South Africa. Current Anthropology 27:135-150.

Squeo, F.A. y J.R. Ehleringer

2004 Isótopos estables: una herramienta común para la ecofisiología vegetal y animal. En Fisiología Ecológica en Plantas: Mecanismos y Respuestas a Estrés en los Ecosistemas, editado por H.M. Cabrera, pp. 59-80. Ediciones Pontificia Universidad Católica de Valparaíso, Valparaíso.

Stehberg, R.

1976 Un sitio alfarero temprano en el interior de la Quinta Normal, Santiago, datado en 180 años a.C. En Homenaje al Dr. Gustavo Le Paige, S.J., editado por H. Niemeyer, pp. 127-140. Universidad del Norte, Antofagasta.

Tieszen, L.L. y M. Chapman

1992 Carbon and nitrogen isotopic status of the major marine and terrestrial resources in the Atacama desert of northern Chile. Proceedings of the First World Congress on Mummy Studies Tomo I, pp. 409-426. Museo Arqueológico y Etnográfico de Tenerife, Cabildo de Tenerife.

Tieszen, L.L., E. Iversen y S. Matzner

1992 Dietary reconstruction based or carbon, nitrogen and sulfur stable isotopes in the Atacama desert, Northern Chile. Proceedings of the First World Congress on Mummy Studies Tomo I, pp. 427-441. Museo Arqueológico y Etnográfico de Tenerife, Cabildo de Tenerife.

Tieszen, L.L. y T. Fagre

1993 Effect of diet quality and composition on the isotopic composition of respiratory $\mathrm{CO} 2$, bone collagen, bio- 
apatite, and soft tissues. En Prehistoric Human Bone: Archaeology at the Molecular Level, editado por J.B. Lambert y G. Grupe, pp. 121-155. Springer-Verlag, New York.

Tomczak, P.D.

2003 Prehistoric diet and socioeconomic relationships within the Osmore Valley of southern Peru. Journal of Anthropological Archaeology 22:262-278.

Tykot, R.H.

2004 Stable isotopes and diet: You are what you eat. En Physics Methods in Archaeometry. Proceedings of the International School of Physics "Enrico Fermi", editado por M. Martini, M. Milazzo y M. Piacentini, pp. 433-444. Societá Italiana di Fisica, Bologna.

van der Merwe, N.J.

1992 Light stable isotopes and the reconstruction of prehistoric diets. Proceedings of the British Academy 77:247-264. van der Merwe, N.J. y J.C. Vogel

$197813 \mathrm{C}$ content of human collagen as a measure of prehistoric diet in Woodland North America. Nature 276:815816. van der Merwe, N.J., R.F. Williamson, S. Pfeiffer, S.C. Thomas y K.O. Allegretto

2003 The Moatfield ossuary: Isotopic dietary analysis of an Iroquoian community, using dental tissue. Journal of Anthropological Archaeology 22:245-261.

Vásquez, M.

2000 Contexto lítico de molienda en el sitio arqueológico El Mercurio, período alfarero temprano de Chile central. Manuscrito en posesión del autor.

Vogel, J.C. y N.J. van der Merwe

1977 Isotopic evidence for early maize cultivation in New York State. American Antiquity 42:238-242.

Walker, P.L. y M.J. DeNiro

1986 Stable nitrogen and carbon isotope ratios in bone collagen as indices of prehistoric dietary dependence on marine and terrestrial resources in Southern California. American Journal of Physical Anthropology 71:51-61.

Wright, L.E. y H.P. Schwarcz

1998 Stable carbon and oxygen isotopes in human tooth enamel: Identifying breastfeeding and weaning in prehistory. American Journal of Physical Anthropology 106:1-18.

\section{Notas}

1 Dicha razón se expresa como delta $(\delta)$ del isótopo más liviano.

2 En este estudio se analizaron los isótopos de oxígeno del carbonato del hueso y del diente, cuya confiabilidad es menor que la del fosfato.

3 Si bien existen valores referenciales para las plantas y la fauna de carácter universal, es recomendable establecer patrones de referencia isotópicos de los recursos locales para asegurar una adecuada interpretación de los resultados.

$4 \quad$ El tipo de estudio realizado se basa en el supuesto que es factible generalizar el tipo de dieta de una población a partir de una muestra de uno o más individuos de esa población, contemplando eventuales variaciones por sexo, edad o identidad social. De la mayoría de los sitios analizados se han recuperado pocos individuos. Nuestra selección no pretende constituir una muestra representativa de cada sitio sino que el criterio de selección fue guiado por el objetivo de reunir un número más o menos paritario de adultos tanto femeninos como masculinos de los distintos contextos culturales y ambientes, donde las variables de conservación y disponibilidad para el estudio fueron determinantes.

5 Los resultados se reportan como razones isotópicas usando la notación delta $(\delta)$ en partes por mil $(\%$ ) en relación a un estándar de laboratorio (PDB para el carbono y AIR o $\mathrm{N}_{2}$ atmosférico para el nitrógeno y SMOW para el oxígeno). En el $\delta^{13} \mathrm{C}$ del colágeno se reportan sólo las muestras que produjeron seudomorfos y una proporción de colágeno en relación a la muestra inicial superior a $1 \%$. El isótopo de carbono del colágeno se especifica como $\delta^{13} \mathrm{Ccol}$ y el de la apatita como $\delta^{13} \mathrm{Cap}$.

6 El escaso control de los valores isotópicos de la fauna de agua dulce del centro de Chile es una limitante en nuestras interpretaciones. Sin embargo, en ninguno de los sitios analizados este tipo de fauna ha sido abundante.

7 Para las estadísticas por grupo cultural, se utilizó un Student t-test no agrupado al 95\%, del programa SYSTAT v. 9.0.

8 En la cuenca de Rancagua, donde se encuentra el sitio Paso Agrícola, aún no se han definido claramente todos los componentes del período Alfarero Temprano. Este individuo representa a grupos no Llolleo de esa zona, con similitudes culturales con los grupos Bato de más al norte.

9 No disponemos del valor $\delta^{15} \mathrm{~N}$ de las algas locales. En diversos estudios se aprecia un amplio rango de $\delta^{15} \mathrm{~N}$ para la vegetación marina, entre 6 y 15\%o (Tomczak 2003; Tieszen y Chapman 1992), lo que hace difícil estimar su incidencia en el valor del nitrógeno humano. 